\title{
Operations Research and cost-effective spatial conservation planning: data, models, tools and future directions
}

\section{Diogo ALAGADOR}

- Biodiversity Chair, MED: Mediterranean Institute for Agriculture, Environment and Development, Universidade de Évora, Rua Joaquim Henrique da Fonseca, Casa Cordovil, 2º , 7000-890 Évora, Portugal; alagador@uevora.pt (ORCID: 0000-0003-0710-3187)

${ }^{*}$ Corresponding author

\section{Jorge Orestes CERDEIRA}

- Department of Mathematics, Faculdade de Ciências e Tecnologia da Universidade NOVA de Lisboa, Quinta da Torre, 282 -516 Costa da Caparica, Portugal; jo.cerdeira@fct.unl.pt (ORCID: 0000-0002-38147660)

- Centre for Mathematics and Applications, Faculdade de Ciências e Tecnologia da Universidade NOVA de Lisboa, Quinta da Torre, 282 -516 Costa da Caparica, Portugal.

\section{ABSTRACT}

Biodiversity conservation questions human practices towards biodiversity and, therefore, largely conflicts with ordinary societal aspirations. Decisions on the location of protected areas, one of the most convincing conservation tools, reflect such a competitive endeavor. Operations Research (OR) brings a set of analytical models and tools capable of resolving the conflicting interests between ecology and economy. Recent technological advances have boosted the size and variety of data available to planners, thus challenging conventional approaches bounded on optimized solutions. New models and methods are requested to use such a massive amount of data in integrative schemes addressing a large variety of concerns. Here, we provide an overview on the past, present and future challenges that characterize spatial conservation models supported by OR. By enlarging the spatial, temporal, taxonomic and societal horizons of biodiversity conservation planners navigate around multiple bio-socioeconomic equilibria and are able to decide on cost-effective strategies to improve biodiversity persistence.

Keywords: Climate change; Ecological dynamics; Mathematical programming; Optimization; Spatial analysis; Systematic Conservation Planning 


\section{ABSTRACT}

Biodiversity conservation questions human practices towards biodiversity and, therefore, largely conflicts with ordinary societal aspirations. Decisions on the location of protected areas, one of the most convincing conservation tools, reflect such a competitive endeavor. Operations Research (OR) brings a set of analytical models and tools capable of resolving the conflicting interests between ecology and economy. Recent technological advances have boosted the size and variety of data available to planners, thus challenging conventional approaches bounded on optimized solutions. New models and methods are requested to use such a massive amount of data in integrative schemes addressing a large variety of concerns. Here, we provide an overview on the past, present and future challenges that characterize spatial conservation models supported by OR. By enlarging the spatial, temporal, taxonomic and societal horizons of biodiversity conservation planners navigate around multiple bio-socioeconomic equilibria and are able to decide on cost-effective strategies to improve biodiversity persistence.

Keywords: Climate change; Ecological dynamics; Mathematical programming; Optimization; Spatial analysis; Systematic Conservation Planning

\section{INTRODUCTION}

The world faces one of the most intractable problems: habitats and species are declining at unprecedented rates (Barnosky et al., 2011; Urban, 2015). Habitat loss, overexploitation of natural resources, biological invasions, pollution and global climate change are major drivers of such declines (Maxwell et al., 2016). In recent decades, the incidence of these threats has been expanding, and their synergistic effects add up to the already broad additive impacts (Barnosky et al., 2011). Globally, multiple institutional instruments have been created to mobilize governments to abate and revert those impacts (e.g., Convention on Biological Diversity, CBD; Intergovernmental Panel on Climate Change, IPCC; Intergovernmental Panel on Biodiversity and Ecosystem Services, IPBES, 2030 United Nations Agenda for Sustainable Development, SDGs). However, the overdependence of modern societies on traditional socioeconomic activities coupled with the unprecedented rates of current climate change makes biodiversity perspectives bleak in the short-term (Seddon et al., 2016; Steffen et al., 2018).

Biodiversity conservation is deeply reliant on functional protected areas (PAs). They are championed as refuges for native species, acting as filters against local threats. Since the establishment of PAs restricts the free practice of socioeconomic activities, PAs are generally 
seen as competing instruments that limit the development of anthropocentric societies, largely reliant on commercial and industrial financial revenues. Under the political sovereignty of shortterm economic gains, governments naturally support biodiversity-hazardous activities, but to pursue the commitments made under global conservation treaties (e.g. Aichi Targets, CBD, 2011; and SDGs, United Nations, 2015), they still need to set aside PAs. In many cases, PAs have been used as figurative political instruments: their establishment is made in regions with low socioeconomic appeal (Joppa and Pfaff, 2009). Consequently, the efforts put into the establishment and management of those PAs are ineffective in accomplishing their ultimate goal of preserving important ecological features (i.e., natural habitats, species' populations and gene pools) and processes (e.g., at the individual level: feeding, mating, resting; at the population level: dispersal, colonization, survivorship and abiotic equilibria, and; at the community level: interaction networks) in the long-term. Without a loss of generality, henceforth, for simplicity, we refer to ecological features and processes as species, since species are the main taxonomic units driving conservation plans.

Thirty years ago, a novel scientific body of research emerged to support transparent and rational decision-making for the identification of ecologically valued areas to protect. Systematic conservation planning (SCP) originated as a framework rendering the interests of researchers, conservationists, policy-makers, managers, stakeholders and citizens in defining the means to conserve not only local natural values, but scaling them up to larger areas and wider sets of decision-makers to accrue the benefits of shared financial resources and complementary conservation actions. This synthesis explores, either directly or indirectly, a small set of questions that emerge from the spatial component of SCP (for comprehensive overviews of SCP see for example McDonald, 2009; McIntosh et al., 2017; Pressey and Bottrill, 2008; Warman et al., 2004), specifically:

- Which species and ecological mechanisms require prioritized protective measures?

- Which processes threaten biodiversity? How can they be integrated in spatial conservation models?

- How are the current and aspiring states of biodiversity quantified? Are there data available or opportunities to gather them?

- How should the financial resources available be spent? (i.e., For which species? In which areas? With what timing? Is it possible to still use the current established conservation efforts?)

- Is it possible to upscale conservation planning towards larger areas and time-horizons, protecting a wider set of species and combining the goals and resources of multiple planners? 
- What are the most effective options for action in contexts characterized by a large risk of failure derived by large amounts of analytical uncertainty and/or stochasticity?

Challenged by these questions, cutting-edge conservation planning uses analytical tools to undertake planning designs that, consequently, are expected to retrieve the largest conservation gains with the least financial resources, alongside a reduction of conflicts with competing socioeconomic activities (Watson et al., 2011). At this stage, solving optimized conservation problems is far from trivial. The need to cover wide sets of species, assessing large geographic areas with detailed (high-resolute) information and the integration of multiple, sometimes interacting, factors makes conservation plans extremely difficult to implement even when supervised by expert knowledge (Langford et al., 2011; Poiani et al., 2000). In this context, Operations Research (OR) gains relevancy as it delivers tools and techniques suited to assist decisions around the spatial (and nonspatial) dimension(s) of conservation planning. In the following sections, we debate problems concerning the spatial component of SCP, in particular, the identification of adequate areas for the establishment of PAs managed uniquely for biodiversity conservation or, similarly, areas where some level of ecologically sustainable socioeconomic development is allowed. We start by describing two general problems in OR that mimic two basic problems in PA selection. Then, we discuss more ambitious area-selection problems that integrate several PA properties and more elaborate conservation concerns (spatial design, connectivity, dynamic PAs prepared to mitigate the effects of climate change; use of explicit socioeconomic data; integration of uncertainty and risk control). We confront custom and ideal spatially explicit datasets informing distinct ecological, budgetary, socioeconomic and vulnerability realities. We conclude, debating about new perspectives to analyze massive amounts of data that, potentially, better represent the broad set of factors likely to determine biodiversity conditions.

\section{THE BASICS OF OR IN SPATIALLY-EXPLICIT BIODIVERSITY CONSERVATION}

Operations Research is a discipline that develops analytical models and methods to help decision-making. It has applications in many fields of science and management, including engineering, economics and logistics, where optimal decisions need to be taken in the presence of trade-offs between two or more conflicting goals (Ravindran, 2008). The cornerstone of OR is optimization, which, in its simplest form, consists of identifying a solution among a set of potential solutions that either maximizes or minimizes an objective function. An OR problem is characterized by a set of constraints that have to be satisfied, outlining if a candidate solution is feasible (when all constraints are fulfilled) or not (when at least one constraint is missed). A 
feasible solution that maximizes (or minimizes) the objective function is called an optimal solution. A problem may have several optimal solutions. Depending on the specific nature of the objective function and constraints, optimization problems are approached by specific methods (e.g., linear, integer, mixed, nonlinear, network, robust, stochastic and dynamic programming procedures) (Hillier and Lieberman, 2015).

In conservation planning, decisions often reflect the interplay of social, economic, political and scientific priorities. The multifactorial dimension of conservation results in contentions and conflicts at the heart of its reasoning. For example, activities that retrieve high financial outcomes may lead to significant ecological disturbance. On the other hand, a conservationist measure may lead to important reductions of agricultural or forestry net production. Once a given criteria of optimality is established (e.g., one that benefits the conservation side of a wide biosocioecological system), it is not possible to achieve it without conflicting with the aspirations of other socioecological players. The complex trade-offs among these factors led Smith and Theberge (1987) and Cocks and Baird (1989) to use OR for the first time in support of spatially based decision-making in conservation. Since then, the use of optimization models in biological conservation research is increasing, both in number and complexity (Figure 1).

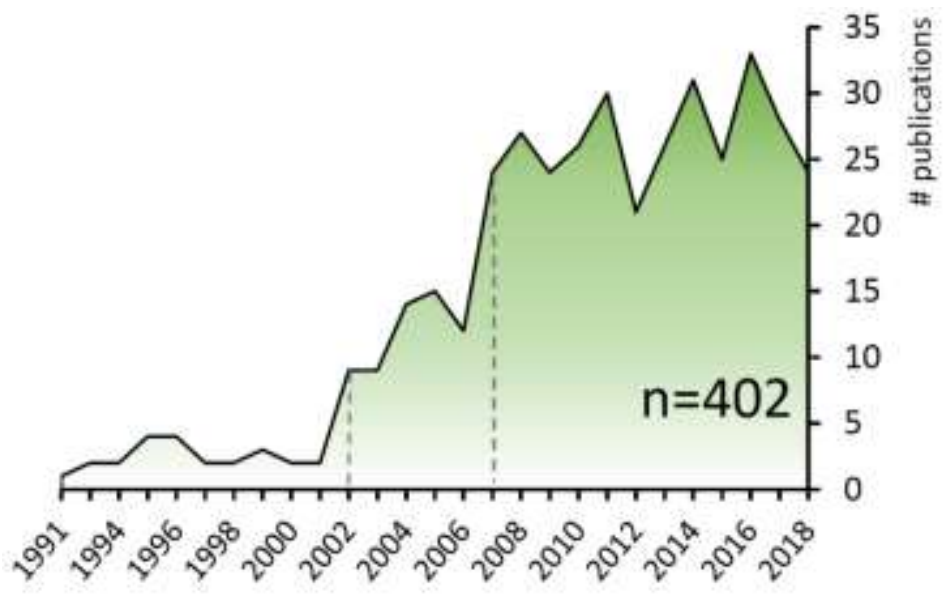

Figure 1 -Yearly number of publications in peer-reviewed journals on ecology and conservation explicitly formulating OR models since 1991 (total number, $n=402$ ). Search on Web of Science at 20 September 2018 [TS = (conservation AND (species OR biodiversity OR habitat*) AND ("integer programming" OR "operations research" OR "mathematical))].

\section{TWO BASIC MODELS AND SOME EXTENSIONS}

Two OR problems were initially proposed to guide spatial conservation decisions for both effectiveness (i.e., accomplishment of established goals) and efficiency (i.e., saving the resources available to undertake conservation decisions and actions). The minimum set cover (MSC) problem aims to choose a subset from the set of candidate selection units (e.g., grid cells in a map 
or, in more general terminology, sites) to build a network of PAs that consume the fewest resources (i.e., number of sites, total surface area, financial resources, etc.), while guaranteeing that each of the species to conserve is adequately covered in those Pas; i.e., the presence of each species within PAs should equalize or exceed a given representation level (i.e., a target) that, ideally, certifies the persistence of a species in the long-term (Justus et al., 2008; Moilanen et al., $2009 b)$. In this problem, sites, as selection units, cannot be partially selected, thus making the problem combinatorial. When a large number of sites and species are analyzed (i.e., ten-tohundreds of thousands), the massive number of combinations to explore (i.e., potential solutions to certify) makes these problems hard to solve to full optimality (Pressey et al., 1996; Rodrigues et al., 2000).

An alternative approach to conservation planning that expresses the context most often faced by conservationists (i.e., the impossibility of protecting all concerned species) assumes that the resources available for the selection of PAs are fixed and limited and conservationists look to maximize the number of species adequately covered by PAs in final solutions (the maximal coverage problem, MC) (Figure 2).
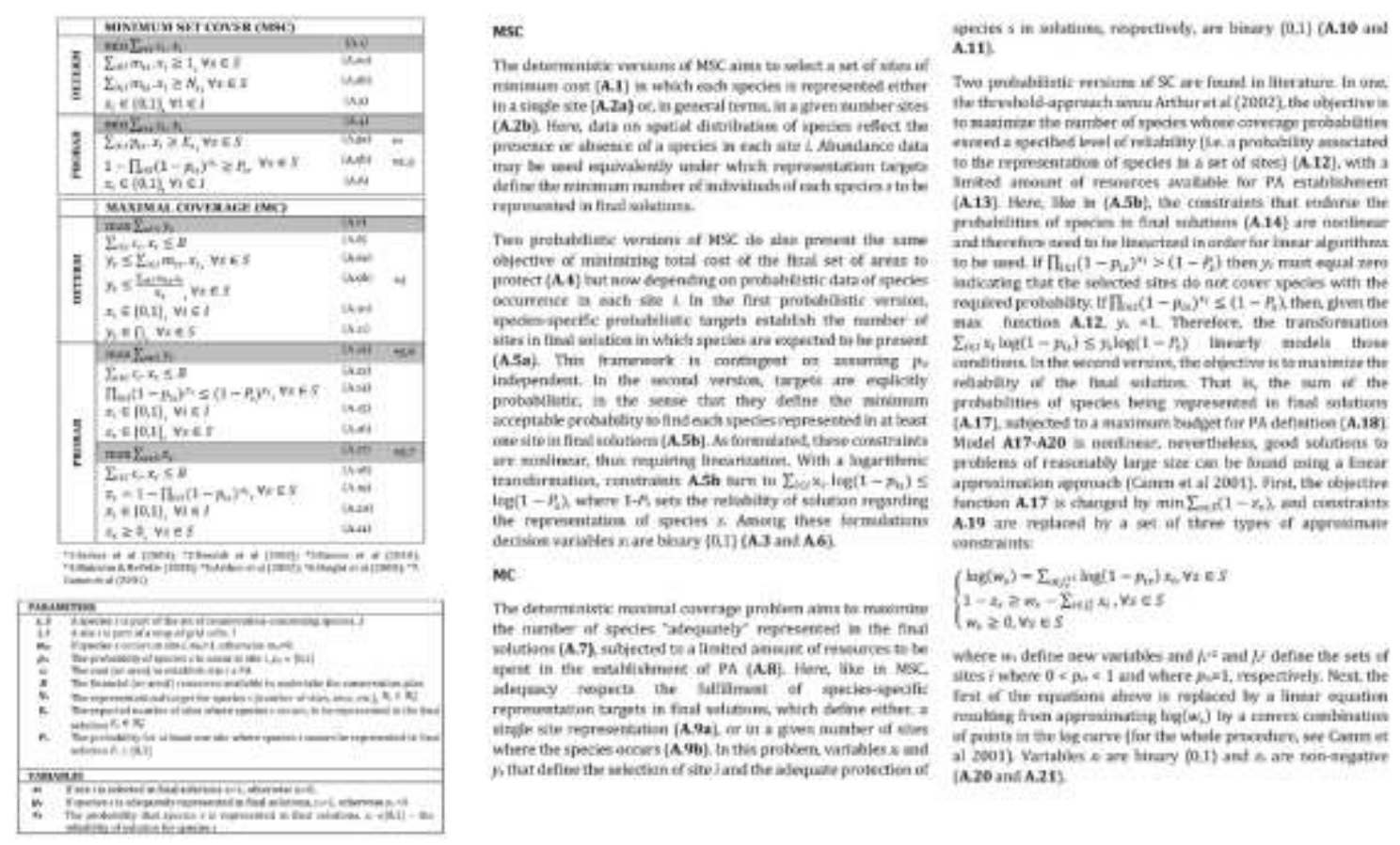

Figure 2 - Formulations of the basic area selection problems.

Originally, both models were built with the general assumption that the representation of a species in a single protected site would suffice to consider the species adequately represented in 
PAs. More general conditions are, however, well accommodated by these problems. For example, the adequate representativeness may differ among species, and/or may require more than one protected site to provide a precautionary, redundant protection. While these generalizations are straightforward and integrated into the MSC, they are slightly less obvious to be accommodated in the MC (Figure 2). Likewise, both problems are flexible on the use of distinct types of data. The use of presence/absence data about each species in each site in the study region may be replaced by (and mixed with) other types of data (e.g., species abundance, local environmental suitability, local probability of occurrence, etc.) (Figure 3). Ultimately, decisions based on data to use and on the settled representation targets should approximate PAs to the leading goal of a conservation plan: to foster biodiversity persistence (Pressey et al., 2007).

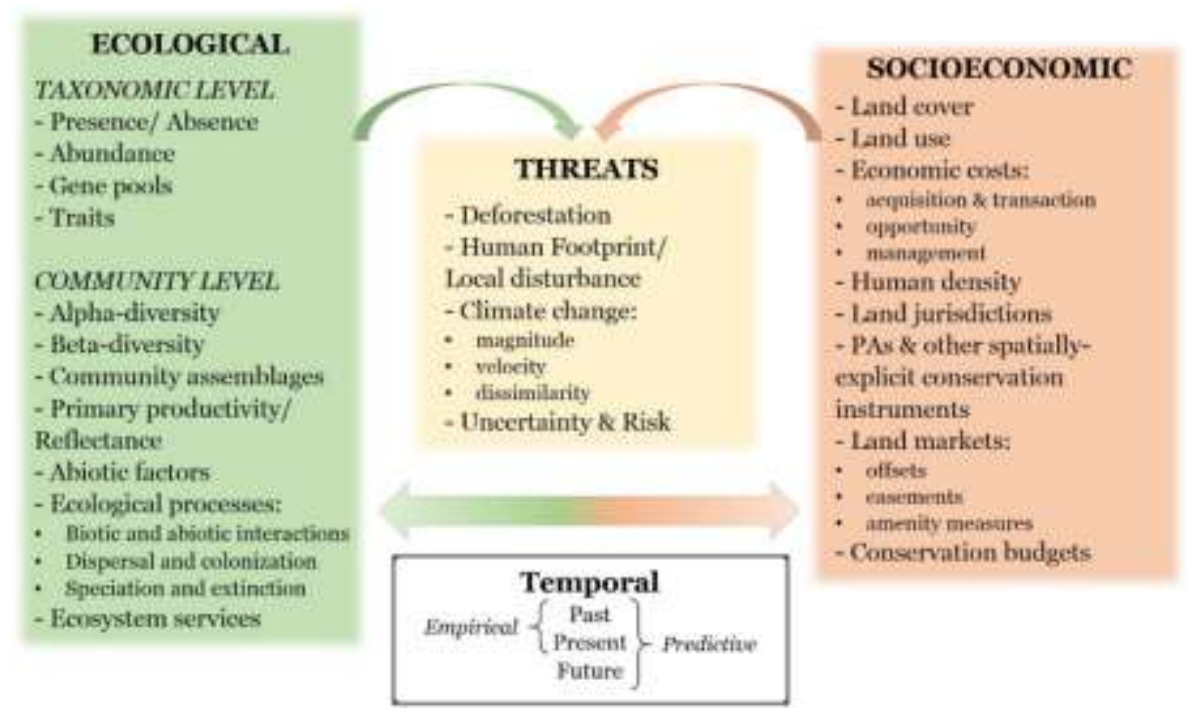

Figure 3 - Relevant data to be used in spatial conservation planning.

Depending on data quality, availability and treatment, planners may consider complementing the representativeness of species in PAs, with PA spatial properties. This choice gains special relevancy when PAs are exposed to detrimental impacts from neighboring regions that may flow into PAs (i.e., edge-effects) or when environmental and/or threat gradients make PA location and design strategic for biodiversity protection. The shape and compactness of PAs (Billionnet, 2015; Nalle et al., 2002; Williams, 2002), length of PA edges (Cerdeira et al., 2005; Fischer and Church, 2003; McDonnell et al., 2002; Önal and Briers, 2002), the number of PA isolates and their proximity (Alagador and Cerdeira, 2007; Cerdeira and Pinto, 2005; Nalle et al., 2002; Önal and Briers, 2002) are spatial attributes (i.e., constraints) that add up to the species' representativeness in MSC and MC problems (see Baskent and Keles, 2005; Billionnet, 2013 for a review on other spatial design models; Williams et al., 2004). Other approaches combine the 
constraints of PA placement and design with species-specific requirements or with the heterogeneity of the landscape. For example, Ciarleglio et al. (2009) and Cerdeira et al. (2010) introduced two unrelated problems in which the cost/area of PA networks is minimized, while cohesive subsets of PAs are identified for each species in which their representation targets are met. Hamaide et al. (2014) formulated the MSC and MC problems attending the risks of expanding threats (e.g., contagious diseases and fires), which are heterogeneously distributed across space. Under their formulations, final solutions are characterized by small PAs, where expanding threats are very likely to occur and large PAs (multiple cohesive protected sites) where these threats are unlikely.

Given that most of the spatial attributes imply nonlinear relationships among sites, to make the problems computationally tractable, when possible, nonlinearities in decision variables need to be linearized (Billionnet, 2014). Linearization usually implies adding more variables and constraints that, altogether, linearly replicate the original nonlinear relationships. Those transformations make solutions harder to obtain when compared with solutions from models that, originally, do not involve nonlinear relationships. However, there is a particular class of nonlinear problems (i.e., their solution space defines a convex set) for which global optima are also obtainable through nonlinear convex optimization methods (Bazaraa et al., 2013).

\section{CONNECTIVITY}

In the previous problems, biodiversity persistence is based on the representativeness of species within PAs and on the effects of heterogeneity, redundancy, and modularity of PA networks for those species. However, those PA selection problems still miss critical factors promoting biodiversity persistence: the natural flows of genes, propagules, individuals, populations and energy across the landscape. A network of PAs that safeguards these processes and that, consequently, circumvents habitat fragmentation is said to be connected. The connectivity of PAs reinforces the dynamic processes and therefore the resiliency of natural (meta)populations to environmental changes (Cabeza et al., 2004; Keith et al., 2008; Minor and Lookingbill, 2010). Depending on the nature of connectivity and the final purpose of a conservation plan, connectivity may be grouped using two classification systems (Correa Ayram et al., 2015). In one, connectivity is said to be structural when it implies the spatial contiguity of sites and is functional when it defines a spatial arrangement of sites in which, being spatially contiguous or not, the flow processes are effectively assured (Calabrese and Fagan, 2004). Under the second classification system, when a conservation plan seeks to identify connected sites (structural or functional) between regions that have been previously targeted as ecologically significant (e.g., 
discrete population units of a species, key habitat patches, PAs, among others), connectivity is said to be primary. Contrarily, when a plan combines connectivity requirements with species representativeness, connectivity is said to be secondary (e.g. Cerdeira et al., 2010; Wang and Önal, 2015). Regardless of the type of connectivity, graphs are adequate mathematical representations. Graphs are mathematical entities settled around a robust theoretical background, which allows solutions to be obtained efficiently (i.e., saving time and computational resources) (Bunn et al., 2000; Urban and Keitt, 2001). In a structural approach, a landscape is well characterized with a single graph describing the spatial arrangement of sites. The sites to be linked are represented by nodes and their topologic relationships (e.g., adjacency, distance, etc.) described by edges linking pairs of nodes. In a functional approach, the specificities associated with each species and flow process imply that a graph (or a set of synthetic graphs) uniquely characterizes a set of species and process with similar connectivity requirements. In these graphs, nodes represent areas of occupancy and/or passages for a species (or where processes flow through) and values associated with edges denote geographic or functional distances between nodes, as perceived by the respective species or characterizing a flow process (e.g., a resistance metric characterizing movement cost across the landscape that depends on habitat characteristics) (Bunn et al., 2000).

Most of the connectivity concerns published in conservation planning literature have focused on primary connectivity using one of three OR problems in graphs (Rayfield et al., 2011): the shortest (or least cost) path (LCP), the minimum spanning tree (MST) and the minimum Steiner tree (MStT) problems. The LCP between a source and a target node (population, habitat, PAs, etc.) in a graph is a path (sequence of nodes and edges) that links the source and target nodes that presents the lowest cumulative cost (i.e., distance or a landscape resistance measure) among the edges that make up the path (Figure 4). One limitation of LCP is that it only predicts connectivity between a single source and a single target node (see Cushman et al., 2009 for an ecological application). Real-world approaches often require more comprehensive assessments of connectivity (Sawyer et al., 2011). For example, planners may require that (if possible) all targeted sites of the study region (special nodes in the graph) are connected together, so that flows exist between every pair of these special nodes (either directly or indirectly through other special nodes) (e.g. Cushman and Landguth, 2012; Fall et al., 2007; Landguth et al., 2012). The MST problem finds such a fully connected solution with the minimum cost. The MStT problem is a generalization of the MST when extra nodes (not necessary to represent important occupancy sites, the Steiner nodes) are defined in the original graph to reduce the cumulative cost of the MST over the original nodes (Sessions, 1992). This problem is more realistic than MST, given that connectivity paths are not limited to strict linkages between pairs of important nodes for 
connecting (e.g. Alagador et al., 2012; Brás et al., 2013; Lai et al., 2011). Possibly, in large inhospitable landscapes, a single (or a set of) habitat center(s) may stay isolated, with no possibility of connecting to the remaining ones. In these cases, planners may consider using generalizations of the MST and MStT that search for the MST and MStT within each isolated set of important areas to link the minimum spanning forest and the Steiner forest problems, respectively (Alagador et al., 2012).

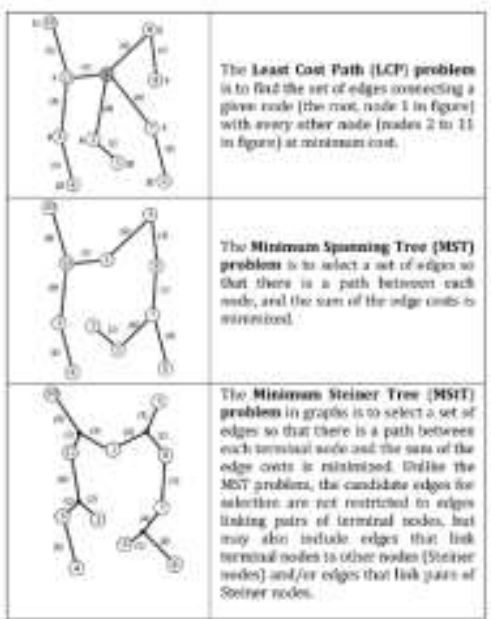

ucp

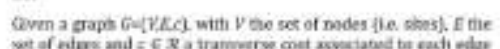

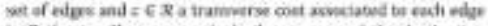
in $E$, if is $t=V$ are respoctimb the source and the destinative

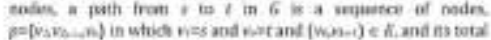
pativivis

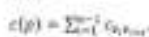

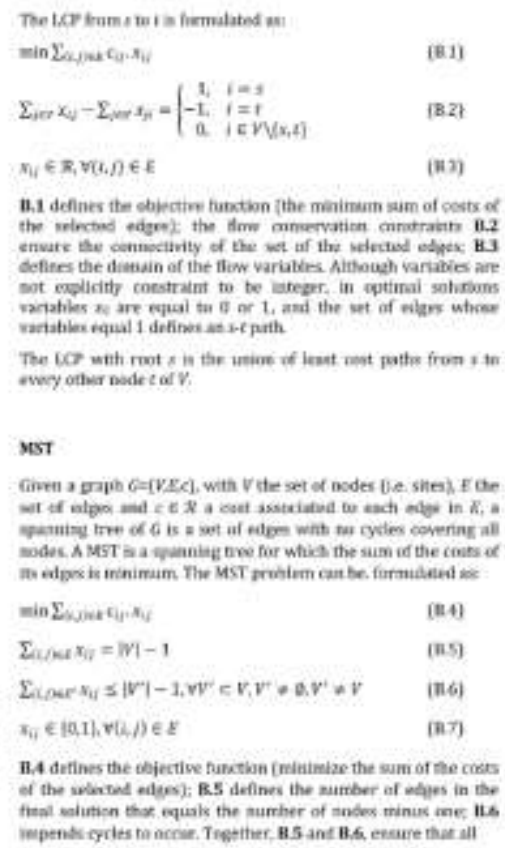

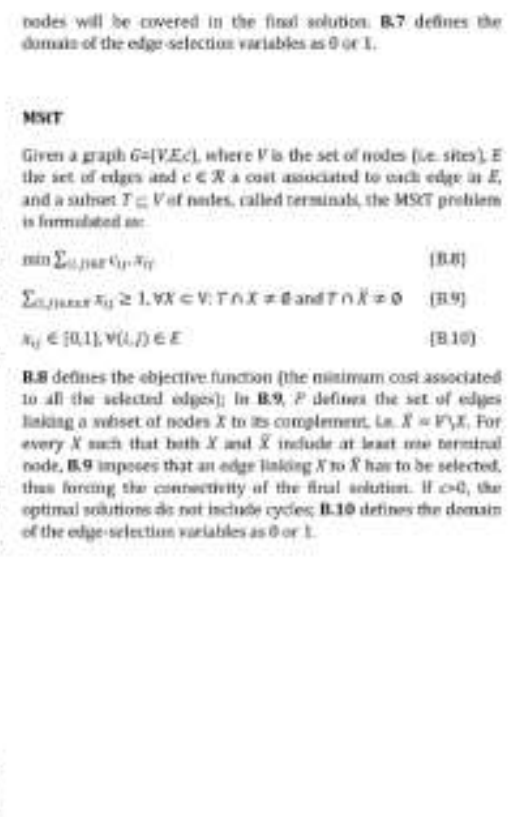

Figure 4 - Formulations of connectivity problems.

A challenge in modeling dispersal routes is that individuals rarely use a single optimum route (Driezen et al., 2007) and therefore the optimum routes obtained from OR problems miss such a variable use of landscape by propagules and individuals (Bélisle, 2005) (unless a minimum number of linkages are defined as a requisite for feasible solutions, Rayfield et al., 2010). For these specific cases, tools derived from the circuit (Dickson et al., 2019; McRae et al., 2008), diffusion (Ovaskainen, 2004) and percolation theories (With, 2002) are best suited to deriving the relative connectivity value of all sites in a map.

\section{MAKING SOCIOECONOMY EXPLICIT}

A central contribution of economists to the development of conservation plans involves the incorporation of financial costs into planning settings. The inclusion of these costs in PA 
selection problems directs the efficiency assessment of plans to financial resources (i.e., budgets) rather than areal size or number of sites (Balmford et al., 2000). When compared to standard area-based procedures, considering financial costs more clearly captures the conservation benefits to be obtained from the investments made, and most likely generates distinct sets of optimal PAs (Ando et al., 1998). Socioeconomic costs associated with conservation plans may include the capital needed: 1) for the acquisition of PAs (i.e., within land markets); 2) to establish time-limited contracts with landowners; 3) to compensate landowners for foregone revenues from their local activities; and 4) to undertake conservation actions, which may depend, for example, on the distance to the established PAs or to operational headquarters of conservation agencies (Naidoo et al., 2006; Naidoo and Ricketts, 2006).

With explicit socioeconomic data available, novel problems arise in which both the revenues from socioeconomics and conservation benefits are optimized. In these multiobjective problems, the maximization of ecological and socioeconomic revenues from PAs is undertaken using distinct analytical designs. With MSC and MC problems, the ecological and financial components of a plan are fixed while the other is maximized. However, when a planner aims to achieve a compromise between the ecological and the socioeconomic goal, multiobjective efficiency frontiers (i.e., Pareto solutions) enable the identification of balanced solutions, in which improving one side of the (socioecological) system implies the reduction of revenues on the other side (Polasky et al., 2008; Polasky et al., 2005). Therefore, they are important states to focus attention on for the purpose of reconciling activity expectations. Conservation costs may also represent nonmarket values that impair conservation effectiveness (Chan et al., 2011); extinction risks associated with species occurring at each site (Game et al., 2008; Tulloch et al., 2013); and measurable uncertainties on local occurrences of species (Kujala et al., 2013; Lemes and Loyola, 2013) (more details below).

Overall, socioeconomic data contribute to making conservation decisions cost-effective in ways that reflect how the nonbiophysical aspects of a conservation plan influence the optimal PA location. These advances do, however, rely on well-functioning institutions, with structured mappings of property rights and comprehensive spatially explicit land-market datasets. The scarcity of these data at workable resolutions limits the applicability of socioeconomic settings in conservation plans, blurring the accuracy of cost-effectiveness metrics in conservation decisions (Armsworth, 2014; Sutton and Armsworth, 2014).

\section{ANTICIPATING FUTURE THREATS}


The PA selection models discussed above are static in the sense that area-selection decisions are exclusively based on information from a single period of time that is implicitly assumed to be stable in the future. However, the pervasive, wide-scaled nature of current threats makes anticipative policies critical for the accomplishment of conservation goals cost-effectively. In these strategies, upfront predictions and inferences concerning the plausible responses of socioecological systems over time put planners one step ahead of possible negative effects, thus causing conservation decisions to be more effective in promoting biodiversity persistence (Hannah et al., 2007). Predictive ecological models that expand empirical data to wide geographic spaces and distant temporal horizons (e.g. species distribution models, Elith and Leathwick, 2009) give planners plausible overviews on future conditions of their working systems (see time dimension in Figure 3). Thus, these tools enable conservation planners to anticipate the management of financial investments over time and to decide which, where and when a conservation action should be undertaken (Mouquet et al., 2015). Proactive approaches resulting from anticipated information are especially relevant when conservation-concerned species are continuously pressed, so that their persistence depends both on the success of their recurrent adaptive responses and the timely adoption of conservation actions (NaujokaitisLewis et al., 2018). Importantly, the way PAs are realized needs to shift from a static, perpetual set of areas, in which species are set aside from local threats, to a network of PAs that, altogether, cover the adaptive movements of species and flow processes with time, favoring their persistence even under global-scale stressors (i.e., dynamic equilibrium) (Hannah, 2008; Hannah et al., 2002a; Hannah et al., 2002b). The unprecedented rate of current and future-predicted climate change and the impacts on biodiversity need to be explicitly accommodated in anticipative conservation planning (Bonebrake et al., in press).

In contrast to local threats that commonly impact local communities as a whole, climate change influences species idiosyncratically, as their genetic, physiological or behavioral adaptive apparatuses lead to specific adaptive responses to the climatic stressors. Climate changeconcerned conservation planners need, therefore, to focus their efforts on these species-specific responses. Under climate change, many species are forced out of PAs (Araújo et al., 2004; Halpin, 1997; Hannah, 2008). Projections indicate that important networks of PAs will lose suitable climates for species of high conservation concern to subsist therein (Araújo et al., 2011; Beale et al., 2013; D'Amen et al., 2011; Hole et al., 2009; Lemes et al., 2014; Prieto-Torres et al., 2016; Regos et al., 2016; Wise et al., 2012). To address this challenge, new PAs need to be planned into the future and their effectiveness re-evaluated through time. The problem is that conservation resources are limited and classifying new PAs to buffer against the negative effects of climate change can be extremely expensive (Hannah et al., 2007; Shaw et al., 2012; Wise et al., 2012). 
Thus, the question is whether efficient strategies can be devised so that long-term conservation targets (e.g., representation targets) are continually met while keeping budgets under control.

Williams et al. (2005) developed a multistage framework (i.e., enabling decisions to be made among several time-steps into the future) with the goal of identifying the sets of areas of minimum cost that cover the adaptive movements of species in a number of unitary dispersal corridors, which define likely trajectories of the species over time within the study region. Later, Phillips et al. (2008) formulated this same problem using classical OR tools from network flow theory. These authors explored special properties in the structure of the modeling networks to make solvable problems dealing with massive datasets. For the same study system, the optimal solution obtained was 30\% less costly than the solution obtained by Williams et al. (2005) using a greedy heuristic approach. Recently, Alagador et al. (2014) and Alagador et al. (2016) proposed several related problems that, instead of a network-like formulation, represent the selection of dispersal corridors as OR-covering problems (line MSC and MC) (Alagador and Cerdeira, under review). In these new problems, representation targets are replaced by persistence targets that rely on the persistence scores of species within dispersal corridors (i.e., the selection units). Although other data may be used to make such scores more accurate, the basic version of persistence scoring uses data reflecting two ecological processes that, depending on availability or planning requirements, are able to be modeled within a gradient of detail: 1 ) the probabilities of a species to occur in a given site in a given time period, and 2) the probabilities of a species to successfully disperse between sites. In a precautionary perspective, the (overall) persistence expectancy of a species in the final solution is obtained through the maximum accumulated persistence in nonconverging dispersal corridors (i.e., a set in which two corridors cannot use the same site in the same period of time). This property of structural independence among dispersal corridors to be used by a species mitigates possible negative contagious effects (e.g., epidemics and fires). Importantly, in these models, area selection is not obligatorily additive, in the sense that, in each time-period, sites that have been previously targeted for protection may be removed from the solution for later periods of time (Fuller et al., 2010). The resources saved from area deselection are then redirected to other areas expected to retrieve the largest gains (considered overall within the objective function). Similar to the original MSC and MC problems, the objective functions of these two equivalent problems are the minimization of total solution cost and the maximization of the number of species "fully covered" (i.e., in these models, representation targets are replaced by persistence targets). Alagador and Cerdeira (2017) introduced a third model in which solution effectiveness is measured using a continuous benefit function. The goal is to minimize the shortfalls to the persistence targets that are minimized over all the focal species. With this objective function, the investments made for 
the protection of a species that miss their persistence targets still profit and, consequently, contribute to the overall solution effectiveness. Importantly, the three problems formulated therein assume that costs on sites vary over time, making them close to real-world dynamic land markets.

Traditional representational targets (i.e., number of sites or total selected area) as settled in the initial PA selection problems have a geographic nature but are established as proxies of species persistence (i.e., the higher the number of sites or the larger their total area, the more likely a species will be maintained). The link between area and persistence is ideally made under the concept of minimum viable population (Clements et al., 2018; Di Marco et al., 2016; Flather et al., 2011; Wiersma and Nudds, 2006), which requires detailed information on population (meta-) dynamics. With these data unavailable, a proximal metric on persistence may be derived using probabilistic or probabilistic-like information on species to define targets using a minimum required persistence threshold for each species (Alagador et al., 2016). However, similar to the probabilistic versions of the MSC and MC problems (see Figure 2), explicit persistence targets do not have an intuitive geographic transposition, making it difficult for a planner to acknowledge aprioristically if a given target is (or is not) achievable by a species within a given conservation setting. This difficultly may result in unfeasible spatial conservation problems, either because at least one persistence target was too inflated given the species condition in the working-system or because a target that, although achievable by a species individually, is not achievable in conjunction with the targets defined for the remaining ones, given the financial resources available for area selection (Alagador and Cerdeira, 2017). To overcome such a drawback, Alagador and Cerdeira (under review) introduced a parameter that enables a planner to relax to $K$ the number of species with their persistence targets fulfilled in final solutions.

\section{DYNAMICS, STOCHASTICITY AND ANTICIPATIVE APPROACHES}

Although imbedding a dynamic selection of PAs over time, the anticipative approaches mentioned above assume a deterministic overview of the future, so that a decision made to protect an area does not change its predicted ecological and socioeconomic states for the time ahead (nor the states of its neighboring areas) (Costello and Polasky, 2004; Polasky, 2006). Similarly, those problems do not assume irreplaceable losses of species occurring in a site when it is left unprotected over time and is fully exposed to local threats (i.e., these sites will contain less conservation value than originally assumed). This conservation template is valid, for example, where protective measures can be applied extensively and rapidly, where the planning domain is public and the loss of native vegetation is unlikely, and when climate change is the 
main factor guiding the establishment of a PA network (in this case, any local conservation action hardly changes the climatic pattern of an area). However, when financial resources are collected incrementally, possibly extending over decades, and where this gradual resourceacquisition is accompanied by a progressive, selective loss of species, then the interplays between the timing of decisions and local land condition and socioeconomic value are best modeled using stochastic dynamic programming (SDP) (Costello and Polasky, 2004; Meir et al., 2004; Strange et al., 2006; Westphal et al., 2003; Wilson et al., 2006). The optimal solution from SDP defines the optimal sequence of decisions when the future status of the sites inside and outside PAs is uncertain and dependent on previous decisions; when these actions present a geographic and/or temporal window of influence; and when stochastic processes prevail

\section{(Figure 5).}
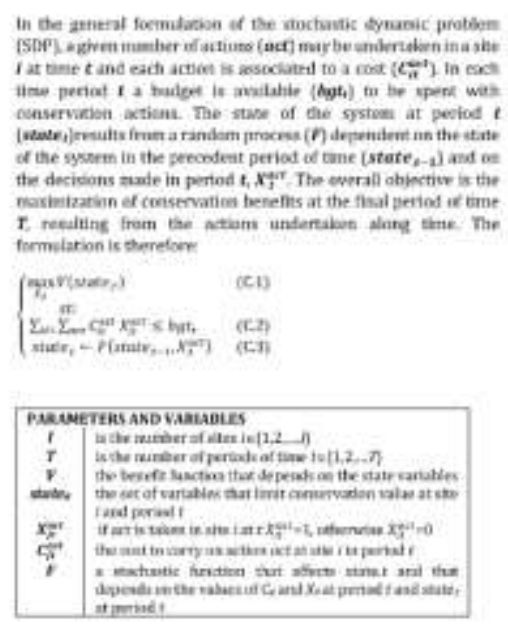

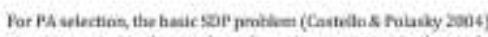
sims os masimise the number of eperkes penesting in the studty

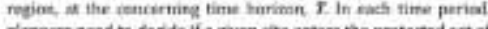

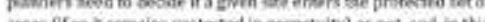

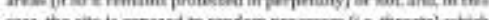

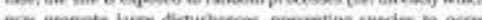

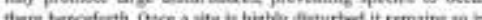
poupesity. The plamer starts with as amallable ludase to spoms

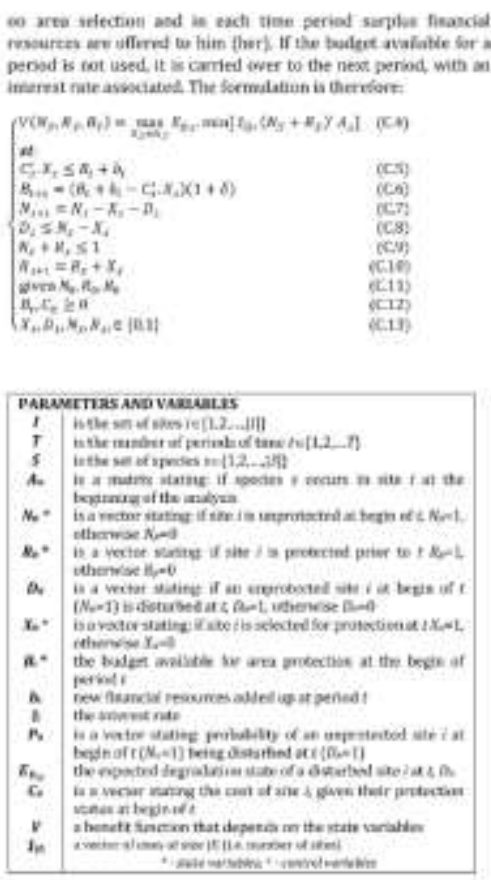

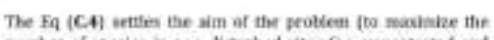

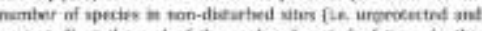
protectod) is the end of the amalyyed period of bome in the

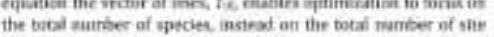

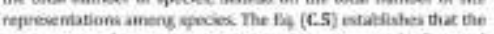

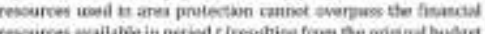

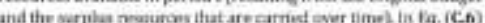

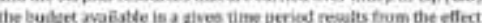

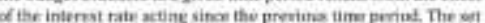

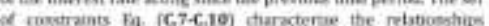

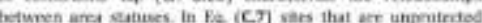

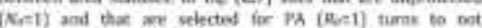

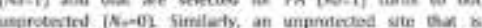

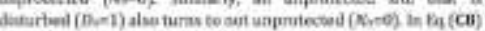

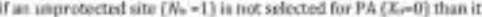

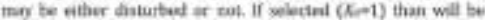

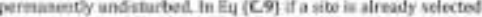

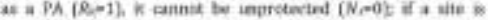

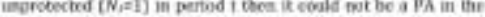

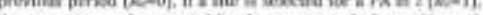

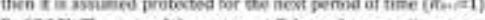

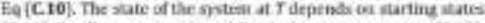

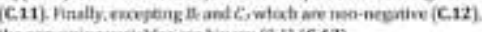
ithe reaening varstles are binary $(0,1)(\mathrm{C}$ 13)

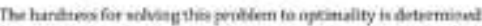
ty the number of sies if) which deflines the mimber of posside

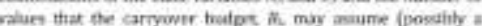

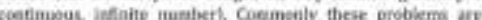

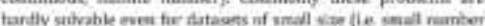

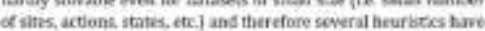

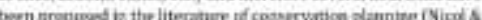
Daftes 2011 \& Cladts in af 2014).

Figure 5 - Formulations of the stochastic dynamic problems (see Costello \& Polasky 2004, for full explanation).

A key advantage of SDP is its ability to produce a feedback policy specifying optimal decisions for possible future system states rather than expected future states (Williams and Johnson, 2013). Depending on the spatial grain, a decision to protect a given site may also influence the condition of sites and species in the neighboring regions. Replicated among the whole landscape, these interdependencies among sites make the problem of selecting Pas, which in the long-term deliver the largest benefits, enormously complex because the computational burden to obtain an optimal solution increases exponentially with the number of sites and system states considered, 
constituting the Bellman's curse of dimensionality (Bellman, 2010). The use of SDP for realistic instances made of hundreds to thousands of sites, several time-periods and several system states is therefore impracticable. To circumvent this drawback, several heuristic approaches have been developed to retrieve suboptimal solutions of good quality (for an overview of such methods in ecology and conservation see Chadès et al., 2014; Nicol and Chadès, 2011; Nicol et al., 2010).

The nature of SDP makes it suitable to explicitly accommodate interrelationships between conservation decisions and land prices. Extensive market feedback determines the effectiveness of conservation investments. First, land prices rise when conservation groups invest significantly in local land markets, making future investments more difficult (Armsworth et al., 2007; Tóth et al., 2011). For example, Armsworth et al. (2006) show how conservation acquisitions alter nearby land values in ways that can accelerate development near PAs. The acquisition of land for additional PAs may increase land prices, making them too expensive for conservation purposes. The assumption of constant marginal land costs neglects land market feedback and underestimates the actual land costs leading to suboptimal solutions (Jantke and Schneider, 2011). In competitive land markets, rental values reflect the supply and demand equilibrium price at a given time and location. When PAs expand over agricultural or forested areas, the equilibrium between supply and demand in regional land markets is distorted and a new equilibrium is obtained with the readjustments of land rental rates. This feedback from land markets affects the economic feasibility of conservation, as along with the costs of future conservation efforts (Polasky, 2006). The more land that is allocated to PAs, the higher are their opportunity costs (e.g., costs of forgone agricultural, forestry production) because of price adjustments in several commodity markets (e.g., agriculture, forest) (Butsic et al., 2013; Dissanayake and Önal, 2011). Commonplace, nonfinancial approaches to PA selection should perform satisfactorily in places where land outside PAs is biodiversity poor. These approaches will fail where, alongside PAs, the countryside surrounding PAs is critical for the species' persistence. In this case, the net gains from conservation investments may be negative, thus making them counterproductive, condemning more species than they save (Armsworth et al., 2006).

Second, conservation investments may displace development pressure locally, and the net biodiversity improvement in the area protected (through full acquisition or rental contracts) may be less than the one expected from the full area purchased. Development pressure can potentially be displaced onto properties of large conservation value that would otherwise have gone unthreatened, meaning that conservation efforts may sometimes do more harm than good (i.e., leakage) (Bode et al., 2014; Moilanen and Laitila, 2016; Renwick et al., 2015). 
Finally, the establishment of PAs can change the overall attractiveness of an area to developers seeking to capitalize on conservation amenities (i.e., amenity values). When acknowledging the ecological value of unprotected land, the effectiveness of conservation efforts is improved by accounting for land market dynamics through reliable data on land rents, land price elasticities and other land market forces (Jantke and Schneider, 2011).

\section{HANDLING UNCERTAINTY AND RISK WITHIN ON LAND DECISIONS}

Economic theory integrates strategies to deal with uncertainty in commercial and financial markets. Conservationists may use some of these strategies to increase the probability of achieving their objectives in contexts wherein distinct types of uncertainty exist (Ando and Hannah, 2011; Langford et al., 2009; Regan et al., 2009). These strategies may be typified as: 1) operational-based: when unmeasurable, uncertainty is handled using spatial-based rules-ofthumb likely to absorb high levels of variability, leading to robust-perceived solutions, or; 2) analytical-based: when uncertainty is measurable (thus referred to as risk), it is typically represented by probabilistic data analyzed statistically. Operational management of uncertainty in PA selection is undertaken, e.g., when conservationists engage in temporary contracts, instead of acquiring areas in perpetuity to keep future conservation options open until uncertainty is resolved (i.e., option value) (Araújo, 2009; Armsworth et al., 2011; Lennox et al., 2017; Newburn et al., 2005; Rissman et al., 2015). Albers et al. (2016) show that a less agglomerated pattern of PAs delivers more insurance against spreading hazards such as fire, invasive species, or pests. Instead of applying investments in neighboring areas with similar characteristics, a precautionary conservationist spreads his (her) investment in mosaics of areas (sets of heterogeneous areas) that, as a whole, are more robust against risk than areas of similar biotic and abiotic characteristics (Anderson and Ferree, 2010; Araújo, 2004; Beier and Brost, 2010; Beier and de Albuquerque, 2015; Lawler et al., 2015).

In terms of risk analysis, modern portfolio theory allows planners to exploit quantitative data about likely correlations between the ecological changes in different areas to choose the collection of lands that, for a given ecological projection, minimizes the uncertainty in the achievement of their goals, e.g., when models retrieve divergent predictions based on several future scenarios (Alvarez et al., 2017; Ando and Mallory, 2012; Doremus, 2003; Hoekstra, 2012; Lahtinen et al., 2017; Liang et al., 2018).

In addition to considering expected returns and standard deviations (risk) of individual investment options, portfolio theory analyzes the covariance structure of investments to limit the aggregated risk of a collection of decisions. A portfolio of investments that covary positively 
would be riskier than one made of decisions whose results covary negatively. Portfolio theory looks to maximize benefits from a given level of risk to minimize risk for a given level of benefit or, through an efficient frontier, to balance benefit and risk in conjunction (Hoekstra, 2012). An info-gap decision model is a meaningful analytical approach to uncertainty when it is so extreme and pernicious that it cannot be dealt with using common probabilistic methods (BenHaim, 2001). This often happens when data are so limited that the associated uncertainty is unmeasurable, so that the parameterization of the study system with a probability distribution is unattainable. An info-gap uncertainty model specifies the levels of uncertainty around each of the model parameters characterizing the system (Figure 6). The parameters are settled as nominal points and, after defining a domain of uncertainty, a window or "horizon" of uncertainty is specified around each nominal point. These levels of (decision) uncertainty are therefore assessed relative to a performance criterion (i.e., the minimum acceptable state of the system). Decisions that cause the system to attain or exceed the performance criterion over a wide range of uncertainty are said to be "robust" or "immune to failure". The other type of immunity deals with decisions that shift the nominal points of the system below the performance criterion. These decisions are not desirable in general, but because a decision spans several possible outcomes, there is always the possibility that the product of the decision is wrong. A question thus remains: what is the smallest level of uncertainty that one needs to assume so that a desirable outcome is possible (but not guaranteed)? Decisions that do not require large amounts of uncertainty to meet this possibility are said to be "opportune" or "less immune to success". There is often a trade-off between decisions that are optimal (i.e., maximize the criterion) and those that are robust to uncertainty (Moilanen et al., 2006; Moilanen and Wintle, 2006). Thus, Regan et al. (2005) and McDonald-Madden et al. (2008) have shown that decisions in endangered species management could change as uncertainty increases or when management criteria change. 


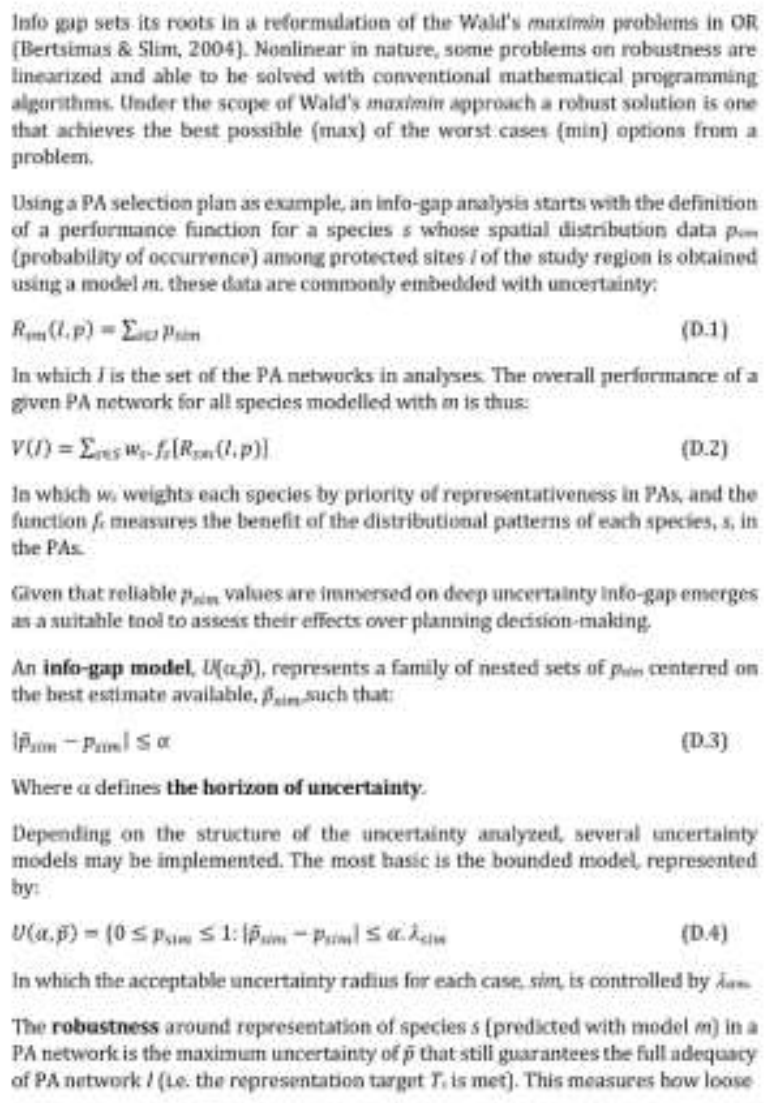

a paramefer defined for species 3 with model $m$ may be in order to maximize the performance of the $\mathrm{PA}$ network for that species:

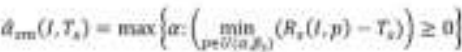

When settied for all the species and for all the models tested (mult-eriteria reward):

$\hat{a}=\max \left\{a \cdot\left(\min \left(\min _{\min }\left(R_{3 \mathrm{sin}}(I, p)-T_{s}\right)\right)\right) \geq 0\right\}=\min \hat{\alpha}_{s m}\left(l, T_{v}\right) \quad$ (D.G)

The PA network 7 is preferred over $P$ if its robustness is greater at the same $T$ fi.e. even with a lange error in estimates attaining a successful performance is still possible],

In order to assess a possible advantageous surprise from uncertainty, driven by opportunities to achieve ambitious standards, then opportuneness should be measured. Opportuneness of a PA network is the minimum uncertainty of $\bar{p}_{\text {, for }}$ which a PA network attains the ambitious performance scenano, A, for every species s. It presents a duat relationshtip with robustness. It is represented as:

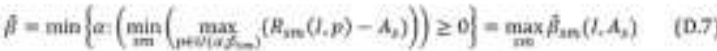

A PA Betwork $/$ is preferred over other $F$ (under the same $A$, ), if its opportuneness. A. is lower [t.e. smail enors in estimates still enable sucoess).

\begin{tabular}{|c|c|}
\hline \multicolumn{2}{|c|}{ PARAMETERS AND VARIABLES } \\
\hline$s$ & a given species from a set of species 5 \\
\hline$m$ & a given model used th describe speries distribution \\
\hline $\boldsymbol{i}$ & a given PA betwork (set of sites), among a set of I PA networles evaluased \\
\hline Pim & probability that species s occurs in site $/$ using model in \\
\hline$\hat{p}_{\text {sise }}$ & best estimate for pur \\
\hline$w_{s}$ & weight apptied to speciess \\
\hline f. & an increasing function on species representation such that, $f(T)=1$ \\
\hline$r$ & representation target for species $s$ in the PA network \\
\hline A. & an anbitious goal, commonily brger than $Y$, \\
\hline$a$ & forizos of encertainty $(a \geq 0)$ \\
\hline $\ln$ & Contruller of the radius of acceptable uncertainty \\
\hline
\end{tabular}

Figure 6 - Formulations of info-gap problems (see Moilanen et al 2006, for full explanation).

Robust optimization is the main method used to address data uncertainty in mathematical programming formulations. This method has been successfully applied to solve many problems (under uncertainty) when the exact probability distribution for the uncertain data is unknown or difficult to determine or otherwise when stochastic optimization techniques are computationally impractical (Gorissen et al., 2015) (Figure 7). Robust optimization problems are computationally tractable, provided the underlying uncertainty sets satisfy mild convexity and computability assumptions (e.g., are given by explicit systems of efficiently computable convex inequalities) (Ben-Tal et al., 2009). Robust optimization is a conservative approach that seeks to protect the decision-maker against the worst realizations of outcomes (Haider et al., 2018). The approach has several appealing features. First, it is explicitly tied to the data available to the decision-maker and captures the idea of robustness with standard likelihood bounds, making the approach both familiar and intuitively appealing. Second, since the approach is numerically tractable, it is applicable to a wide range of problems. Finally, because the framework allows policy-makers to choose the degree of precaution desired and map this level of precaution into a dynamically optimal policy, it has direct relevance and a clear structure for managers (Woodward and Tomberlin, 2014). 


\begin{abstract}
In the generic optimization problem (Le. linear programming. LP): $\quad \min _{x}\left[c^{7} x A x \leq b\right]$
The data comprise the numerical values of the entries in $(c ; A ; b)$.

In Robust Optimization, an uncertain L.P problem is defined as a colloction of L.P programs of a common

structure with the data $(c, A ; b)$ varying in a given uncertainty set $u$

$\left\{\min _{x}\left[c^{r} x, A x \leq b\right] \div(c, A, b) \in u\right\}$

(E.1)

Conceptually, the most important question is what does it mean to solve an uncertain L.P problem. The answer to this question rests on the definition of a "immune to uncertainty' solution. Indeed, this solution should be a fixed vector $x$ that make the solution feasible for the constraints, whatever the realization of the data within $u$. Such a solution is called robust feasibje. Among other possibilities in the decision-making environment (Greenberg \& Morrison 2008) meaningful robust solutions, $x$, to an uncertain problem may be oriented by the "worst-case" viewpoint, that is, that guarantees that the worst-vohe (i.e supreme) of E.1 is minimized. Thus, the best possible robust feasible solution is the one that solves the optimization problem

$\min _{x}\left\{\max _{(c, d), v e}\left(c^{T} x: A x \leq b\right):(c, A, b) \in u\right\}$

(E.2)

That is, "robust solutions" remain feasible and near-optimal regardless of how the data changes: However, robustness comes with a price, as robust solutions can be costly compared to an expected value approach - solutions are too conservative in the sense that much of optimality is gave up for the nominal problem to be robust. An extension of worst-case optimization involves specifying a different level of risk of violation for each constraint (Bertsimas and Sim, 2004), which is beneficial as it allows the decision-maker to assume greater risk with some constraints, thereby reducing the cost of the robust solution.
\end{abstract}

Figure 7 - Formulations of general robust-optimization problems.

Classical (frequentist) and Bayesian statistical analyses dedicated to the integration of uncertainty in decision-making problems use probabilistic distributions to define a controlled spectra of possible outputs from decisions through confidence intervals (Burgman et al., 2005; Gelman and Hill, 2006; Lin et al., 2018) or to identify conditions that ensure, with a given probability, a certain ideal output is obtained (Carroll et al., 2010; Schapaugh and Tyre, 2012). Both approaches enter an optimization protocol with the incorporation of uncertainty functions on parameter values (probabilistic and belief models, for the frequentist and Bayesian paradigms, respectively), which are integrated into the objective function. The Bayesian approaches present the advantage of providing sequential updates of belief functions (specified in terms of model parameters) as new information is acquired through time (e.g., adaptive decisions) (McDonald-Madden et al., 2010; Sanderlin et al., 2014; Wade, 2000).

\title{
9. CHALLENGES AHEAD - THE WAY FORWARD
}

With thirty years of growth, the spatial dimension of SCP is now facing challenging times, in which large problems need quick responses. Although the protection of biodiversity is not commonly driven by societal requirements (i.e. the no-value land paradigm, Joppa and Pfaff, 2009; Venter et al., 2018), human aspirations still need to be integrated into its machinery so that achievable win/win scenarios are identified, making conservation goals better supported 
(Fahrenkamp-Uppenbrink, 2014; Howe et al., 2014; Reyers et al., 2012). These requirements give conservation planning the need to be more realistic by: 1) gathering more and better data; 2) building flexible decision support models able to characterize a wide array of realities; and 3) promoting stakeholder engagement across the full SCP process, to: 3.1 ) find consensual and explicit goals; 3.2) use proper models to fulfil those goals in each particular study system, and 3.3) evaluate and reformulate provisional solutions. In this multiplayer framework, we perform an overview of some challenges that the quantitative module of conservation planning already faces or will face in the short-term.

\subsection{Building more realistic assumptions}

The multidimensional complexity of biodiversity conservation demands access to a wide set of accurate data for planning designs to be effective in maximizing biodiversity persistence. Information on the distribution, abundance and dynamics of genes, populations, species and biotic communities; plausible changes in environmental, physical, social and economic drivers; and the impacts of global environmental changes should be collected at the spatial and temporal scales matching the relevancy of the phenomena and the established goals (Figure 3). Importantly:

- Good quality data with high-resolute spatial grain allow a large number of decisions to be evaluated and therefore to enlarge the analytical space to look for the most informative solutions;

- The increase of geographic windows allows the expansion of political, jurisdictional and institutional scopes of biodiversity conservation to profit not only from the individual potential of each player but, mainly, from collaborations and shared goals. In wide geographic contexts, detailed data of local ecological and socioeconomic processes approximate conservation plans to the real scales in which key biodiversity processes operate, especially when environments are heterogeneous and dynamic (e.g., the "geography of species' adaptations" to climate change);

- High-resolute temporal data allow planners to strengthen the control of their conservation systems, making them capable of opening up opportunities for quicker readjustments of conservation actions. With the tendency for a massive array ofecological data to be available, the monitoring of conservation systems may operate similarly to the (quasi-) continuous scanning performed within meteorological and climate assessments (Kissling et al., 2018; Proença et al., 2017). Precautionary approaches demand that actions today are made for plausible scenarios ahead. Thus, 
expanding the time horizon of conservation plans allows a plausible future to be anticipated, leading to informed-proactive preparation of the expected outcomes and therefore more robust PA mappings. The extension of future temporal data implies large predictive capabilities for the environmental, the ecological and the socioeconomic systems. The farthest in the future they are, the more uncertain the predictions (Northrop and Chandler, 2014). This temporal gradient of uncertainty needs to also be accommodated in conservation planning models (see time-varying costs, interest rates, SDP and robust optimization, above);

- Biodiversity refers to structural elements (i.e., genes, populations, species, communities and ecosystems) that have coevolved over thousands of years and the complex multiscaled processes (e.g., physiological, genetic, behavioral, ecological, evolutionary, abiotic) that generate and link them together and sustain the whole. Expanded data on the evolutionary, genetic, taxonomic and functional components of biodiversity permit planners to control the countless aspects that act at multiple scales and allow ecosystems to be, by definition, dynamic and complex. The realization of these kind of data demand the emergence of hierarchical nonlinear decision-support models and powerful algorithms to be developed and/or accessed.

In the age of big data (Farley et al., 2018), raising the quantity and quality standards of data; identifying interrelationships among data types and making a wide set of analytical tools available offers planners the flexibility in tailoring a conservation plan to the idiosyncrasies of their contextual working systems. These datasets may establish seedlings for the advance of conservation plans under different viewpoints, different solution philosophies and goals (Bayraktarov et al., 2019). With this flexibility comes the burden of choice and, fortunately, with OR, the set from which to make that choice grows (Figure 3 \& Figure 8). 


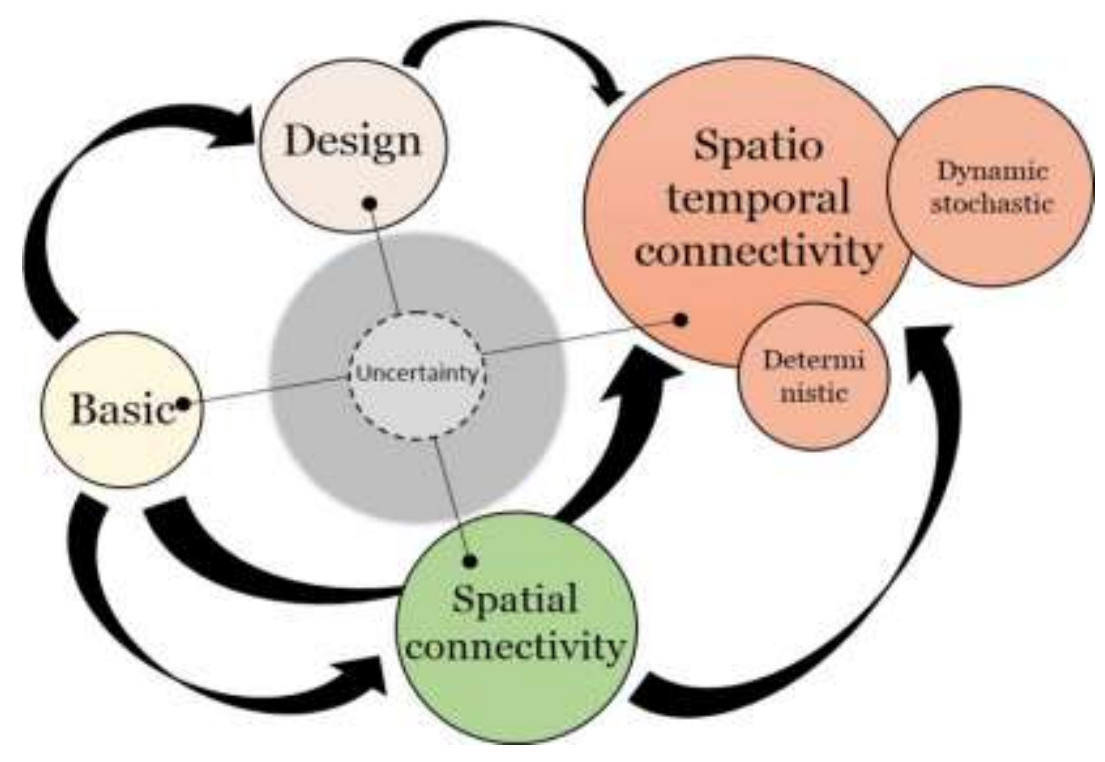

Figure 8 -Classes of OR area selection models, their hardness in finding full-optimal solutions (size of circles) and their potential inter-relationships (arrows). Predictive uncertainty, with varied nature and magnitude, is combinable among all model types.

\subsection{Placement and management decisions}

With its multiscaled structure, conservation plans need to be comprehensive and to incorporate important components of SCP. For example, conservation models need not only support decisions about the timing and location of PAs but also quantify which/where/when conservation actions (e.g., threat prevention, monitoring, and effective management actions) should be taken and distributed. Given the feedback characterizing these systems, models of this type require an improved biosocioeconomic realism and a continuous supply of data (Williams and Johnson, 2013; Wilson et al., 2011).

Future research should analyze operational decisions, such as the allocation of personnel resources, equipment and other assets among different treatment sites, and the routing of crews between selected sites for management (Sewell et al., 2012; Yokomizo et al., 2004). Deployment of multiple resources such as funding and labor among different management options, over multiple areas and time periods, is also another possible future direction (i.e., logistical problems). Paralleling area selection, the scheduling of management actions and the allocation of tasks among personnel are other relevant issues for future investigation (Adams and Setterfield, 2015; Baker and Bode, 2016; Moore and McCarthy, 2016; Watts et al., 2009; Wilson et al., 2011). Another interesting research line is the coordination of capacity (e.g., personnel and equipment) and governance (e.g., local, regional, national responsibilities) among stakeholders. In particular, cooperation among independent but related parties to share their resources, capacities, and information could improve the efficiency of PAs (Frank and Sarkar, 2010). Operations Research models have been widely used to supply chain coordination among stakeholders in production 
and manufacturing, disaster management and bioterrorism response (Altay and Green, 2006; Ravindran, 2008). Future studies should incorporate the risks of invasive species related to transportation in an optimization model in which the routes, through which manufactures (e.g., wood, food) are transferred, are optimally selected while minimizing the distances that potential invaders are transported (Büyüktahtakın and Haight, 2017). Network optimization models, such as LCP and minimum cost network flow problems (Ahuja et al., 1993) can be used to formulate the transportation of goods that pose an invasion risk (see Connectivity section and Figure 4). Future research may consider the optimization of the transportation network and the selection of appropriate means for transportation and distribution activities while minimizing the risk of introduction and the establishment of new invaders (Courtois et al., 2018; Yemshanov et al., 2017).

\subsection{Coordination among multiple stakeholders}

Biodiversity conservation crosses jurisdictional boundaries since it constitutes a platform to respond to the adaptive spatial responses of biodiversity to expanding, globalized threats. The fitness of populations and the way they spread depend on the choices made by several decisionmakers in organized or less structured bodies of governance. Each conservation agency typically decides on where, when and how to undertake formal decisions on conservation based on local damage and management costs, without considering the benefits of protection generated by actions already made in neighboring regions by other conservation players. Therefore, independent agents are likely to underinvest in conservation from a societal perspective. The cooperative or centralized control of conservation planning across jurisdictions delivers superior performances when compared with independent decision-making (Albers et al., 2008; Kroetz and Sanchirico, 2015). A mechanism of transfer payments in which one jurisdiction pays another to increase their level of decision (Bhat and Huffaker, 2007) is one method of cooperation. In other situations, jurisdictions may simply agree to coordinate their efforts in a beneficial way to minimize spillover effects (Epanchin-Niell and Wilen, 2015). Cooperative game theory (Curiel, 2013), a branch of OR specifically devoted to explicit or implicit strategy coordination, may be used to determine compensation efforts and optimal cooperation among multiple stakeholders (Alvarado-Quesada and Weikard, 2017b; Epanchin-Niell and Wilen, 2012, 2015; Frank and Sarkar, 2010; Iacona et al., 2016). Few studies have compared the distribution of PAs derived from coarse-scale (regional) and fine-scale (local) data, but these have demonstrated significant cost-effective differences (Kukkala et al., 2016; Moilanen and Arponen, 2011; Pouzols et al., 2014). At many spatial scales, decisions are likely to be under the purview of groups rather than individuals, and the size, composition and organization of groups are likely to 
vary with the geographical scale (Alvarado-Quesada and Weikard, 2017a; Frank and Sarkar, 2010). Different types of uncertainty and risk prevail at (and percolate between) different scales in ways that are difficult to quantify. The design of market-based and regulatory policies to enhance cooperation across jurisdictions is a primary area of further research.

\subsection{Computational infrastructures}

The computational burden of dealing with realistic spatial conservation planning have remained the greatest challenge to implement OR models and to obtain optimal or good quality suboptimal solutions (Beyer et al., 2016; Song et al., 2018). The growing number of powerful computational facilities has provided the background for the establishment of consortia in which computational scientists collaborate with conservation planners (La Salle et al., 2016). Under these partnerships, while data analysts and managers are challenged by real-world problems inspiring them to develop and test new models and techniques, conservation planners are offered access to state-of-the-art computational tools allowing "good quality solutions" to be obtained. The field of computational sustainability (Lässig et al., 2016) has paved the way for interdisciplinary calls for the development of techniques from computer and information science and related disciplines (e.g., OR, applied mathematics and statistics) to trade-off environmental, economic and societal needs and aspirations so that sustainable development is accomplished (Gomes, 2011). Logistically, these consortia enable ecological data-intensive problems to be solved in high performance computing infrastructures (e.g., cluster and grid computing), thus allowing researchers to make use of tens of thousands of dedicated servers to execute coordinated solving tasks (Abreu et al., 2014). Fast and cheap local cluster computing is now possible through offthe-shelf computational nodes and software, allowing the easy construction and maintenance of supercomputers. For example, while LIFEWatch-ERIC (https://www.lifewatch.eu), ELIXIR (https://www.elixir-europe.org) and EUBrazilOpenBio (http://www.eubrazilopenbio.eu) are key initiatives already in place, they still lack spatial conservation planning modules that may provide the crucial link from ecological sciences to policy-making. We envisage a wide range of opportunities for interdisciplinary expansion in the short-term.

In addition to the full use of available computing infrastructures, the work undertaken by operations researchers should not be neglected. They formulate problems and conceive dedicated algorithms for solving very particular questions (i.e., large analytical resolution). Until now, the use of Marxan (Ball et al., 2009), Zonation (Moilanen et al., 2009a) and other easy to use software (for a list see http://conservationcorridor.org/corridor-toolbox/programs-and-tools/ and https://applcc.org/plan-design/gis-planning/conservation-planning/conservation- 
planning-software) has been commonplace in many published studies, but these tools were not always properly developed to deal with very particular contingencies and requirements. Possibly, many researchers have chosen to simplistically adapt their studies to the principles of such general models. "Wasting" time in mathematical clarification (i.e., formulation) of a conservation problem may retrieve fruitful results later on, by either, maximizing the utility of the proposed solutions, minimizing their associated costs or, ideally, both.

In summary, emerging tools, technologies, infrastructures and information technology partnerships in the age of big data may boost state-of-the-art approaches for better research and management, and may alter how conservation planning is looked at even from inside, opening opportunity-windows for fundamental advances and applied research, thus making biodiversity conservation effective and acute over time.

\section{CONCLUSIONS}

1. Biodiversity conservation considers several problems wherein conservation interests compete with the socioeconomic expectations that govern modern societies. In this context, the scarce resources available for planning, acquisition and management of PAs need to be optimally distributed.

2. Given that the current biodiversity crisis impacts a wide set of biological features and processes, spans large regions and is likely to subsist in time, the combinatorial nature of conservation decisions makes real-world conservation problems hardly solvable by intuition alone.

3. Operations Research (with particular emphasis on optimization) offers powerful tools and methods for planners and policy-makers make the "best" decisions. Under the OR framework, decision problems need to be defined, analyzed and solved using a rational, systematic and scientific design, based on data, facts, information and logic, and not on mere guesswork or rules-of-thumb.

4. The dynamic and complex nature of conservation systems and the increasing availability of ecological, socioeconomic and institutional data still challenge the way OR delivers good-quality solutions. More elaborated models able to deal with a large array of factors need to be developed and critically discussed and upgraded with stakeholder involvement.

5. Fusing together the spatial, temporal and management dimensions of conservation plans; dealing with multiscaled agents and budgets within coordinated schemes; and promoting 
collaborative consortia with shared interests provide the modern ingredients to achieve a paramount societal goal: to preserve biodiversity under grand challenging scenarios.

\section{ACKNOWLEDGEMENTS}

This research was funded by FEDER funds through the Fundação para a Ciência e a Tecnologia (FCT) and Programa Operacional Factores de Competitividade - COMPETE - and was undertaken under the projects PTDC/AAG-GLO/3979/2014 (ref. 9471-RIDTI) and UID/MAT/00297/2019. D.A. received support through a FCT's postdoctoral fellowship SFRH/BPD/104077/2014. The authors have no conflicts of interest to declare.

\section{REFERENCES}

Abreu, S., Munera, D., Diaz, D., 2014. Towards a Parallel Hierarchical Adaptive Solver Tool, Workshop on Parallel Methods for Search \& Optimization (ParSearchOpt14).

Adams, V.M., Setterfield, S.A., 2015. Optimal dynamic control of invasions: applying a systematic conservation approach. Ecological Applications 25(4) 1131-1141.

Ahuja, R.K., Magnanti, T.L., Orlin, J.B., 1993. Network Flows: Theory, Algorithms and Applications. Prentice Hall, Upper Saddle River, New Jersey, USA.

Alagador, D., Cerdeira, J.0., 2007. Designing spatially-explicit reserve networks in the presence of mandatory sites. Biological Conservation 137(2) 254-262.

Alagador, D., Cerdeira, J.O., 2017. Meeting species persistence targets under climate change: A spatially explicit conservation planning model. Diversity and Distributions 23(6) 703-713.

Alagador, D., Cerdeira, J.O., under review. Revisiting the minimum set cover, the maximal coverage models and a maximum benefit area selection model to make climate-change-concerned conservation plans effective.

Alagador, D., Cerdeira, J.O., Araújo, M.B., 2014. Shifting protected areas: scheduling spatial priorities under climate change. Journal of Applied Ecology 51(3) 703-713.

Alagador, D., Cerdeira, J.O., Araújo, M.B., 2016. Climate change, species range shifts and dispersal corridors: an evaluation of spatial conservation models. Methods in Ecology and Evolution 7(7) 853-866.

Alagador, D., Triviño, M., Cerdeira, J., Brás, R., Cabeza, M., Araújo, M., 2012. Linking like with like: optimising connectivity between environmentally-similar habitats. Landscape Ecology 27(2) 291-301. Albers, H.J., Ando, A.W., Batz, M., 2008. Patterns of multi-agent land conservation: Crowding in/out, agglomeration, and policy. Resource and Energy Economics 30(4) 492-508. 
Albers, H.J., Busby, G.M., Hamaide, B., Ando, A.W., Polasky, S., 2016. Spatially-Correlated Risk in Nature Reserve Site Selection. PLoS ONE 11(1) e0146023.

Altay, N., Green, W.G., 2006. OR/MS research in disaster operations management. European Journal of Operational Research 175(1) 475-493.

Alvarado-Quesada, I., Weikard, H.-P., 2017a. International cooperation on biodiversity conservation when spatial structures matter. Spatial Economic Analysis 12(1) 27-49.

Alvarado-Quesada, I., Weikard, H.-P., 2017b. International Environmental Agreements for biodiversity conservation: a game-theoretic analysis. International Environmental Agreements: Politics, Law and Economics 17(5) 731-754.

Alvarez, S., Larkin, S.L., Ropicki, A., 2017. Optimizing provision of ecosystem services using modern portfolio theory. Ecosystem Services 27 25-37.

Anderson, M.G., Ferree, C.E., 2010. Conserving the stage: climate change and the geophysical underpinnings of species diversity. PLoS ONE 5(7) e11554.

Ando, A., Camm, J., Polasky, S., Solow, A., 1998. Species distributions, land values, and efficient conservation. Science 279(5359) 2126-2128.

Ando, A.W., Hannah, L.E.E., 2011. Lessons from Finance for New Land-Conservation Strategies Given Climate-Change Uncertainty. Conservation Biology 25(2) 412-414.

Ando, A.W., Mallory, M.L., 2012. Optimal portfolio design to reduce climate-related conservation uncertainty in the Prairie Pothole Region. Proceedings of the National Academy of Sciences 109(17) 6484-6489.

Araújo, M.B., 2004. Matching species with reserves - uncertainties from using data at different resolutions. Biological Conservation 118(4) 533-538.

Araújo, M.B., 2009. Protected areas and climate change in Europe: A discussion paper prepared for the 29th meeting of the Standing Committee, Convention on the Conservation of European Wildlife and Natural Habitats, Strasbourg, 23-26 November 2009. Council of Europe, p. 29.

Araújo, M.B., Alagador, D., Cabeza, M., Nogués-Bravo, D., Thuiller, W., 2011. Climate change threatens European conservation areas. Ecology Letters 14 484-492.

Araújo, M.B., Cabeza, M., Thuiller, W., Hannah, L., Williams, P.H., 2004. Would climate change drive species out of reserves? An assessment of existing reserve-selection methods. Global Change Biology 10(9) 16181626.

Armsworth, P.R., 2014. Inclusion of costs in conservation planning depends on limited datasets and hopeful assumptions. Annals of the New York Academy of Sciences 1322(1) 61-76. 
Armsworth, P.R., Cantú-Salazar, L., Parnell, M., Davies, Z.G., Stoneman, R., 2011. Management costs for small protected areas and economies of scale in habitat conservation. Biological Conservation 144(1) 423-429.

Armsworth, P.R., Chan, K.M.A., Daily, G.C., Ehrlich, P.R., Kremen, C., Ricketts, T.H., Sanjayan, M.A., 2007. Ecosystem-Service Science and the Way Forward for Conservation. Conservation Biology 21(6) 13831384.

Armsworth, P.R., Daily, G.C., Kareiva, P., Sanchirico, J.N., 2006. Land market feedbacks can undermine biodiversity conservation. Proceedings of the National Academy of Sciences of the United States of America 103(14) 5403-5408.

Baker, C.M., Bode, M., 2016. Placing invasive species management in a spatiotemporal context. Ecological Applications 26(3) 712-725.

Ball, I.R., Possingham, H.P., Watts, M., 2009. Marxan and relatives: Software for spatial conservation prioritisation, In: Moilanen, A., Wilson, K.A., Possingham, H.P. (Ed.), Spatial conservation prioritisation: Quantitative methods and computational tools. Oxford University Press: Oxford, UK, pp. 185-195. Balmford, A., Gaston, K.J., Rodrigues, A.S.L., James, A., 2000. Integrating costs of conservation into international priority setting. Conservation Biology 14(3) 597-605.

Barnosky, A.D., Matzke, N., Tomiya, S., Wogan, G.O.U., Swartz, B., Quental, T.B., Marshall, C., McGuire, J.L., Lindsey, E.L., Maguire, K.C., Mersey, B., Ferrer, E.A., 2011. Has the Earth's sixth mass extinction already arrived? Nature 471(7336) 51-57.

Baskent, E.Z., Keles, S., 2005. Spatial forest planning: A review. Ecological Modelling 188(2-4) 145-173.

Bayraktarov, E., Ehmke, G., O'Connor, J., Burns, E.L., Nguyen, H.A., McRae, L., Possingham, H.P., Lindenmayer, D.B., 2019. Do Big Unstructured Biodiversity Data Mean More Knowledge? Frontiers in Ecology and Evolution 6(239).

Bazaraa, M.S., Sherali, H.D., Shetty, C.M., 2013. Nonlinear programming: theory and algorithms. John Wiley \& Sons.

Beale, C.M., Baker, N.E., Brewer, M.J., Lennon, J.J., 2013. Protected area networks and savannah bird biodiversity in the face of climate change and land degradation. Ecology Letters 16(8) 1061-1068.

Beier, P., Brost, B., 2010. Use of land facets to plan for climate change: conserving the arenas, not the actors. Conservation Biology 24(3) 701-710.

Beier, P., de Albuquerque, F.S., 2015. Environmental diversity as a surrogate for species representation. Conservation Biology 29(5) 1401-1410.

Bélisle, M., 2005. Measuring landscale connectivity: the challenge of behavioral ladscape ecology. Ecology 86(8) 1988-1995.

Bellman, R., 2010. Dynamic Programming. Princeton University Press. 
Ben-Haim, Y., 2001. Information Gap Decision Theory: Decisions under Severe Uncertainty. Academic Press, San Diego, CA, USA; London, UK.

Ben-Tal, A., El Ghaoui, L., Nemirovski, A., 2009. Robust optimization. Princeton University Press. Beyer, H.L., Dujardin, Y., Watts, M.E., Possingham, H.P., 2016. Solving conservation planning problems with integer linear programming. Ecological Modelling 328 14-22.

Bhat, M.G., Huffaker, R.G., 2007. Management of a transboundary wildlife population: A self-enforcing cooperative agreement with renegotiation and variable transfer payments. Journal of Environmental Economics and Management 53(1) 54-67.

Billionnet, A., 2013. Mathematical optimization ideas for biodiversity conservation. European Journal of Operational Research 231(3) 514-534.

Billionnet, A., 2014. Quadratic Optimization in 0-1 Variables. Concepts of Combinatorial Optimization 189-233.

Billionnet, A., 2015. Designing Connected and Compact Nature Reserves. Environmental Modeling \& Assessment 21(2) 211-219.

Bode, M., Tulloch, A.I.T., Mills, M., Venter, O., W. Ando, A., 2014. A conservation planning approach to mitigate the impacts of leakage from protected area networks. Conservation Biology n/a-n/a.

Bonebrake, T.C., Guo, F., Dingle, C., Baker, D.M., Kitching, R.L., Ashton, L.A., in press. Integrating Proximal and Horizon Threats to Biodiversity for Conservation. Trends in Ecology \& Evolution.

Brás, R., Cerdeira, J.O., Alagador, D., Araújo, M.B., 2013. Linking habitats for multiple species.

Environmental Modelling \& Software 40(0) 336-339.

Bunn, A.G., Urban, D.L., Keitt, T.H., 2000. Landscape connectivity: A conservation application of graph theory. Journal of Environmental Management 59(4) 265-278.

Burgman, M.A., Lindenmayer, D.B., Elith, J., 2005. Managing landcapes for conservation under uncertainty. Ecology 86(8) 2007-2017.

Butsic, V., Lewis, D.J., Radeloff, V.C., 2013. Reserve selection with land market feedbacks. Journal of Environmental Management 114(0) 276-284.

Büyüktahtakın, İ.E., Haight, R.G., 2017. A review of operations research models in invasive species management: state of the art, challenges, and future directions. Annals of Operations Research.

Cabeza, M., Moilanen, A., Possingham, H.P., 2004. Metapopulation dynamics and reserve network design, In: Hanski, I., Gaggiotti, O.E. (Eds.), Ecology, genetics, and evolution of metapopulations. Elsevier Academic Press: London.

Calabrese, J.M., Fagan, W.F., 2004. A comparison-shopper's guide to connectivity metrics. Frontiers in Ecology and the Environment 2(10) 529-536. 
Carroll, C., Johnson, D.S., Dunk, J.R., Zielinski, W.J., 2010. Hierarchical Bayesian spatial dodels for multispecies conservation planning and monitoring. Conservation Biology 24(6) 1538-1548.

CBD, 2011. Conference of the Parties Decision X/2: Strategic plan for biodiversity 2011-2020.

Cerdeira, J.O., Gaston, K.J., Pinto, L.S., 2005. Connectivity in priority area selection for conservation. Environmental Modeling \& Assessment 10(3) 183-192.

Cerdeira, J.O., Pinto, L., 2005. Requiring Connectivity in the Set Covering Problem. Journal of Combinatorial Optimization 9(1) 35-47.

Cerdeira, J.O., Pinto, L.S., Cabeza, M., Gaston, K.J., 2010. Species specific connectivity in reserve-network design using graphs. Biological Conservation 143(2) 408-415.

Chadès, I., Chapron, G., Cros, M.-J., Garcia, F., Sabbadin, R., 2014. MDPtoolbox: a multi-platform toolbox to solve stochastic dynamic programming problems. Ecography 37(9) 916-920.

Chan, K.M.A., Hoshizaki, L., Klinkenberg, B., 2011. Ecosystem services in conservation planning: targeted benefits vs. co-Benefits or costs? PLoS ONE 6(9) e24378.

Ciarleglio, M., Wesley Barnes, J., Sarkar, S., 2009. ConsNet: new software for the selection of conservation area networks with spatial and multi-criteria analyses. Ecography 32(2) 205-209.

Clements, H.S., Kearney, S.G., Cook, C.N., 2018. Moving from representation to persistence: The capacity of Australia's National Reserve System to support viable populations of mammals. Diversity and Distributions 24(9) 1231-1241.

Cocks, K.D., Baird, I.A., 1989. Using Mathematical-Programming to Address the Multiple Reserve Selection Problem - an Example from the Eyre Peninsula, South-Australia. Biological Conservation 49(2) 113-130.

Correa Ayram, C.A., Mendoza, M.E., Etter, A., Salicrup, D.R.P., 2015. Habitat connectivity in biodiversity conservation: A review of recent studies and applications. Progress in Physical Geography.

Costello, C., Polasky, S., 2004. Dynamic reserve site selection. Resource and Energy Economics 26 157174.

Courtois, P., Figuieres, C., Mulier, C., Weill, J., 2018. A Cost-Benefit Approach for Prioritizing Invasive Species. Ecological Economics 146 607-620.

Curiel, I., 2013. Cooperative Game Theory and Applications: Cooperative Games Arising From Combinatorial Optimization Problems. Springer Science \& Business Media.

Cushman, S.A., Landguth, E.L., 2012. Multi-taxa population connectivity in the Northern Rocky Mountains. Ecological Modelling 231(0) 101-112.

Cushman, S.A., McKelvey, K.S., Schwartz, M.K., 2009. Use of empirically derived source-destination models to map regional conservation corridors. Conservation Biology 23(2) 368-376. 
D'Amen, M., Bombi, P., Pearman, P.B., Schmatz, D.R., Zimmermann, N.E., Bologna, M.A., 2011. Will climate change reduce the efficacy of protected areas for amphibian conservation in Italy? Biological Conservation 144 989-997.

Di Marco, M., Santini, L., Visconti, P., Mortelliti, A., Boitani, L., Rondinini, C., 2016. Using habitat suitability models to scale up population persistence targets. Hystrix, the Italian Journal of Mammalogy; Vol 27, No 1 (2016).

Dickson, B.G., Albano, C.M., Anantharaman, R., Beier, P., Fargione, J., Graves, T.A., Gray, M.E., Hall, K.R., Lawler, J.J., Leonard, P.B., Littlefield, C.E., McClure, M.L., Novembre, J., Schloss, C.A., Schumaker, N.H., Shah, V.B., Theobald, D.M., 2019. Circuit-theory applications to connectivity science and conservation. Conservation Biology 33(2) 239-249.

Dissanayake, S.T.M., Önal, H., 2011. Amenity driven price effects and conservation reserve site selection: A dynamic linear integer programming approach. Ecological Economics 70(12) 2225-2235.

Doremus, H., 2003. A policy portfolio approach to biodiversity protection on private lands. Environmental Science \& Policy 6(3) 217-232.

Driezen, K., Adriaensen, F., Rondinini, C., Doncaster, C.P., Matthysen, E., 2007. Evaluating least-cost model predictions with empirical dispersal data: A case-study using radiotracking data of hedgehogs (Erinaceus europaeus). Ecological Modelling 209(2) 314-322.

Elith, J., Leathwick, J.R., 2009. Species distribution models: ecological explanation and prediction across space and time. Annual Review of Ecology, Evolution, and Systematics 40(1) 677-697.

Epanchin-Niell, R.S., Wilen, J.E., 2012. Optimal spatial control of biological invasions. Journal of Environmental Economics and Management 63(2) 260-270.

Epanchin-Niell, R.S., Wilen, J.E., 2015. Individual and cooperative management of invasive species in human-mediated landscapes. American journal of agricultural economics 97(1) 180-198.

Fahrenkamp-Uppenbrink, J., 2014. How to achieve win-win outcomes for biodiversity. Science 346(6209) 596.

Fall, A., Fortin, M.-J., Manseau, M., O'Brien, D., 2007. Spatial graphs: principles and applications for habitat connectivity. Ecosystems 10 448-461.

Farley, S.S., Dawson, A., Goring, S.J., Williams, J.W., 2018. Situating Ecology as a Big-Data Science: Current Advances, Challenges, and Solutions. BioScience 68(8) 563-576.

Fischer, D.T., Church, R.L., 2003. Clustering and compactness in reserve site selection: An extension of the Biodiversity Management Area Selection model. Forest Science 49(4) 555-565.

Flather, C.H., Hayward, G.D., Beissinger, S.R., Stephens, P.A., 2011. Minimum viable populations: is there a 'magic number' for conservation practitioners? Trends in Ecology \& Evolution 26(6) 307-316. 
Frank, D.M., Sarkar, S., 2010. Group Decisions in Biodiversity Conservation: Implications from Game Theory. PLoS ONE 5(5) e10688.

Fuller, R.A., McDonald-Madden, E., Wilson, K.A., Carwardine, J., Grantham, H.S., Watson, J.E.M., Klein, C.J., Green, D.C., Possingham, H.P., 2010. Replacing underperforming protected areas achieves better conservation outcomes. Nature 466(7304) 365-367.

Game, E.T., Watts, M.E., Wooldridge, S., Possingham, H.P., 2008. Planning for persistence in marine reserves: a question of catastrophic importance. Ecological Applications 18(3) 670-680.

Gelman, A., Hill, J., 2006. Data analysis using regression and multilevel/hierarchical models. Cambridge university press.

Gomes, C.P., 2011. Computational Sustainability. Springer Berlin Heidelberg: Berlin, Heidelberg, pp. 8-8. Gorissen, B.L., Yanıkoğlu, İ., den Hertog, D., 2015. A practical guide to robust optimization. Omega 53 124137.

Haider, Z., Charkhgard, H., Kwon, C., 2018. A robust optimization approach for solving problems in conservation planning. Ecological Modelling 368 288-297.

Halpin, P.N., 1997. Global climate change and natural-area protection: Management responses and research directions. Ecological Applications 7(3) 828-843.

Hamaide, B., Albers, H.J., Busby, G., 2014. Backup coverage models in nature reserve site selection with spatial spread risk heterogeneity. Socio-Economic Planning Sciences 48(2) 158-167.

Hannah, L., 2008. Protected areas and climate change. Annals of the New York Academy of Sciences 1134(1) 201-212.

Hannah, L., Midgley, G.F., Andelman, S., Araújo, M.B., Hughes, G., Martinez-Meyer, E., Pearson, R.G., Williams, P.H., 2007. Protected area needs in a changing climate. Frontiers in Ecology and Environment 5(3) 131-138.

Hannah, L., Midgley, G.F., Lovejoy, T., Bond, W.J., Bush, M., Lovett, J.C., Scott, D., Woodward, F.I., 2002a. Conservation of biodiversity in a changing climate. Conservation Biology 16(1) 264-268.

Hannah, L., Midgley, G.F., Millar, D., 2002b. Climate change-integrated conservation strategies. Global Ecology and Biogeography 11(6) 485-495.

Hillier, F.S., Lieberman, G.J., 2015. Introduction to Operations Research, 10th edition ed. McGraw-Hill Education, New York, USA.

Hoekstra, J., 2012. Improving biodiversity conservation through modern portfolio theory. Proceedings of the National Academy of Sciences 109(17) 6360-6361.

Hole, D.G., Willis, S.G., Pain, D.J., Fishpool, L.D., Butchart, S.H.M., Collingham, Y.C., Rahbek, C., Huntley, B., 2009. Projected impacts of climate change on a continent-wide protected area network. Ecology Letters 12 (5) 420-431. 
Howe, C., Suich, H., Vira, B., Mace, G.M., 2014. Creating win-wins from trade-offs? Ecosystem services for human well-being: A meta-analysis of ecosystem service trade-offs and synergies in the real world. Global Environmental Change 28 263-275.

Iacona, G.D., Bode, M., Armsworth, P.R., 2016. Limitations of outsourcing on-the-ground biodiversity conservation. Conservation Biology 30(6) 1245-1254.

Jantke, K., Schneider, U.A., 2011. Integrating Land Market Feedbacks into Conservation Planning-A Mathematical Programming Approach. Environmental Modeling \& Assessment 16(3) 227-238.

Joppa, L.N., Pfaff, A., 2009. High and Far: Biases in the Location of Protected Areas. PLoS ONE 4(12) e8273.

Justus, J., Fuller, T., Sarkar, S., 2008. Influence of representation targets on the total area of conservationarea networks. Conservation Biology 22 673-682.

Keith, D.A., Akçakaya, H.R., Thuiller, W., Midgley, G.F., Pearson, R.G., Phillips, S.J., Regan, H.M., Araújo, M.B., Rebelo, T.G., 2008. Predicting extinction risks under climate change: coupling stochastic population models with dynamic bioclimatic habitat models. Biology Letters 4(5) 560-563.

Kissling, W.D., Ahumada, J.A., Bowser, A., Fernandez, M., Fernández, N., García, E.A., Guralnick, R.P., Isaac, N.J.B., Kelling, S., Los, W., McRae, L., Mihoub, J.-B., Obst, M., Santamaria, M., Skidmore, A.K., Williams, K.J., Agosti, D., Amariles, D., Arvanitidis, C., Bastin, L., De Leo, F., Egloff, W., Elith, J., Hobern, D., Martin, D., Pereira, H.M., Pesole, G., Peterseil, J., Saarenmaa, H., Schigel, D., Schmeller, D.S., Segata, N., Turak, E., Uhlir, P.F., Wee, B., Hardisty, A.R., 2018. Building essential biodiversity variables (EBVs) of species distribution and abundance at a global scale. Biological Reviews 93(1) 600-625.

Kroetz, K., Sanchirico, J.N., 2015. The Bioeconomics of Spatial-Dynamic Systems in Natural Resource Management. Annual Review of Resource Economics 7(1) 189-207.

Kujala, H., Burgman, M.A., Moilanen, A., 2013. Treatment of uncertainty in conservation under climate change. Conservation Letters 6(2) 73-85.

Kukkala, A.S., Arponen, A., Maiorano, L., Moilanen, A., Thuiller, W., Toivonen, T., Zupan, L., Brotons, L., Cabeza, M., 2016. Matches and mismatches between national and EU-wide priorities: Examining the Natura 2000 network in vertebrate species conservation. Biological Conservation 198 193-201.

La Salle, J., Williams Kristen, J., Moritz, C., 2016. Biodiversity analysis in the digital era. Philosophical Transactions of the Royal Society B: Biological Sciences 371(1702) 20150337.

Lahtinen, T.J., Hämäläinen, R.P., Liesiö, J., 2017. Portfolio decision analysis methods in environmental decision making. Environmental Modelling \& Software 94 73-86.

Lai, K.J., Gomes, C.P., Schwartz, M.K., McKelvey, K.S., Calkin, D.E., Montgomery, C.A., 2011. The Steiner multigraph problem: wildlife corridor design for multiple species, In: Burgard, W.R., D. (Ed.), Proceedings of the Twenty-Fifth AAAI Conference on Artificial Intelligence (AAAI-11). AAAI Press: San Francisco, CA, USA, p. 8. 
Landguth, E.L., Hand, B.K., Glassy, J., Cushman, S.A., Sawaya, M.A., 2012. UNICOR: a species connectivity and corridor network simulator. Ecography 35(1) 9-14.

Langford, W.T., Gordon, A., Bastin, L., 2009. When do conservation planning methods deliver? Quantifying the consequences of uncertainty. Ecological Informatics 4(3) 123-135.

Langford, W.T., Gordon, A., Bastin, L., Bekessy, S.A., White, M.D., Newell, G., 2011. Raising the bar for systematic conservation planning. Trends in Ecology \& Evolution 26(12) 634-640.

Lässig, J., Kersting, K., Morik, K., 2016. Computational Sustainability. Springer International Publishing. Lawler, J.J., Ackerly, D.D., Albano, C.M., Anderson, M.G., Dobrowski, S.Z., Gill, J.L., Heller, N.E., Pressey, R.L., Sanderson, E.W., Weiss, S.B., 2015. The theory behind, and the challenges of, conserving nature's stage in a time of rapid change. Conservation Biology 29(3) 618-629.

Lemes, P., Loyola, R.D., 2013. Accommodating species climate-forced dispersal and uncertainties in spatial conservation planning. PLoS ONE 8(1) e54323.

Lemes, P., Melo, A., Loyola, R., 2014. Climate change threatens protected areas of the Atlantic Forest. Biodiversity and Conservation 23(2) 357-368.

Lennox, G.D., Fargione, J., Spector, S., Williams, G., Armsworth, P.R., 2017. The value of flexibility in conservation financing. Conservation Biology 31(3) 666-674.

Liang, J., Gao, X., Zeng, G., Hua, S., Zhong, M., Li, X., Li, X., 2018. Coupling Modern Portfolio Theory and Marxan enhances the efficiency of Lesser White-fronted Goose's (Anser erythropus) habitat conservation. Scientific Reports 8(1) 214.

Lin, Y.-P., Lin, W.-C., Anthony, J., Ding, T.-S., Mihoub, J.-B., Henle, K., Schmeller, D.S., 2018. Assessing uncertainty and performance of ensemble conservation planning strategies. Landscape and Urban Planning 169(Supplement C) 57-69.

Maxwell, S.L., Fuller, R.A., Brooks, T.M., Watson, J.E., 2016. Biodiversity: The ravages of guns, nets and bulldozers. Nature 536(7615) 143.

McDonald-Madden, E., Baxter, P.W.J., Possingham, H.P., 2008. Making robust decisions for conservation with restricted money and knowledge. Journal of Applied Ecology 45(6) 1630-1638.

McDonald-Madden, E., Probert, W.J.M., Hauser, C.E., Runge, M.C., Possingham, H.P., Jones, M.E., Moore, J.L., Rout, T.M., Vesk, P.A., Wintle, B.A., 2010. Active adaptive conservation of threatened species in the face of uncertainty. Ecological Applications 20(5) 1476-1489.

McDonald, R.I., 2009. The promise and pitfalls of systematic conservation planning. Proceedings of the National Academy of Sciences 106(36) 15101-15102.

McDonnell, M.D., Possingham, H.P., Ball, I.R., Cousins, E.A., 2002. Mathematical methods for spatially cohesive reserve design. Environmental Modeling \& Assessment 7(2) 107-114. 
McIntosh, E.J., Pressey, R.L., Lloyd, S., Smith, R., Grenyer, R., 2017. The Impact of Systematic Conservation Planning. Annual Review of Environment and Resources 42(1) null.

McRae, B.H., Dickson, B.G., Keitt, T.H., Shah, V.B., 2008. Using circuit theory to model connectivity in ecology, evolution and conservation. Ecology 89(10) 2712-2724.

Meir, E., Andelman, S., Possingham, H.P., 2004. Does conservation planning matter in a dynamic and uncertain world? Ecology Letters 7(8) 615-622.

Minor, E.S., Lookingbill, T.R., 2010. A multiscale network Analysis of protected-area connectivity for mammals in the United States. Conservation Biology 24(6) 1549-1558.

Moilanen, A., Arponen, A., 2011. Administrative regions in conservation: Balancing local priorities with regional to global preferences in spatial planning. Biological Conservation 144(5) 1719-1725.

Moilanen, A., Kujala, H., Leathwick, J.R., 2009a. The Zonation Framework and Software for Conservation Prioritization, In: Moilanen, A., Possingham, H., K., W. (Eds.), Spatial Conservation Prioritization:

Quantitative Methods and Computational Tools. Oxford University Press: Oxford, UK, pp. 196-210.

Moilanen, A., Laitila, J., 2016. Indirect leakage leads to a failure of avoided loss biodiversity offsetting. Journal of Applied Ecology 53(1) 106-111.

Moilanen, A., Possingham, H.P., Polasky, S., 2009b. A Mathematical Classification of Conservation Prioritization Problems, In: Moilanen, A., Possingham, H., K., W. (Eds.), Spatial Conservation Prioritization: Quantitative Methods and Computational Tools. Oxford University Press, pp. 28-42.

Moilanen, A., Runge, M.C., Elith, J., Tyre, A., Carmel, Y., Fegraus, E., Wintle, B.A., Burgman, M., Ben-Haim, Y., 2006. Planning for robust reserve networks using uncertainty analysis. Ecological Modelling 199(1) 115124.

Moilanen, A., Wintle, B.A., 2006. Uncertainty analysis favours selection of spatially aggregated reserve networks. Biological Conservation 129(3) 427-434.

Moore, A.L., McCarthy, M.A., 2016. Optimizing ecological survey effort over space and time. Methods in Ecology and Evolution 7(8) 891-899.

Mouquet, N., Lagadeuc, Y., Devictor, V., Doyen, L., Duputié, A., Eveillard, D., Faure, D., Garnier, E., Gimenez, O., Huneman, P., Jabot, F., Jarne, P., Joly, D., Julliard, R., Kéfi, S., Kergoat, G.J., Lavorel, S., Le Gall, L., Meslin, L., Morand, S., Morin, X., Morlon, H., Pinay, G., Pradel, R., Schurr, F.M., Thuiller, W., Loreau, M., 2015. Predictive ecology in a changing world. Journal of Applied Ecology 52(5) 1293-1310.

Naidoo, R., Balmford, A., Ferraro, P.J., Polasky, S., Ricketts, T.H., Rouget, M., 2006. Integrating economic costs into conservation planning. Trends in Ecology \& Evolution 21(12) 681-687.

Naidoo, R., Ricketts, T.H., 2006. Mapping the economic costs and benefits of conservation. PLoS Biology $4(11)$ e360. 
Nalle, D.J., Arthur, J.L., Sessions, J., 2002. Designing compact and contiguous reserve networks with a hybrid heuristic algorithm. Forest Science 48(1) 59-68.

Naujokaitis-Lewis, I., Pomara, L.Y., Zuckerberg, B., 2018. Delaying conservation actions matters for species vulnerable to climate change. Journal of Applied Ecology 55(6) 2843-2853.

Newburn, D., Reed, S., Berck, P., Merenlender, A., 2005. Economics and land-use change in prioritizing private land conservation. Conservation Biology 19(5) 1411-1420.

Nicol, S., Chadès, I., 2011. Beyond stochastic dynamic programming: a heuristic sampling method for optimizing conservation decisions in very large state spaces. Methods in Ecology and Evolution 2(2) 221228.

Nicol, S.C., Chadès, I., Linke, S., Possingham, H.P., 2010. Conservation decision-making in large state spaces. Ecological Modelling 221(21) 2531-2536.

Northrop, P.J., Chandler, R.E., 2014. Quantifying Sources of Uncertainty in Projections of Future Climate. Journal of Climate 27(23) 8793-8808.

Önal, H., Briers, R.A., 2002. Incorporating spatial criteria in optimum reserve network selection. Proceedings of the Royal Society of London Series B-Biological Sciences 269(1508) 2437-2441.

Ovaskainen, O., 2004. Habitat-specific movement parameters estimated using mark-recapture data and a diffusion model. Ecology 85(1) 242-257.

Phillips, S., Williams, P., Midgley, G., Aaron, A., 2008. Optimizing dispersal corridors for the Cape Proteaceae using network flow. Ecological Applications 18 1200-1211.

Poiani, K.A., Richter, B.D., Anderson, M.G., Richter, H.E., 2000. Biodiversity conservation at multiple scales: Functional sites, landscapes, and networks. BioScience 50(2) 133-146.

Polasky, S., 2006. You can't always get what you want: conservation planning with feedback effects. Proceedings of the National Academy of Sciences of the United States of America 103(14) 5245-5246. Polasky, S., Nelson, E., Camm, J., Csuti, B., Fackler, P., Lonsdorf, E., Montgomery, C., White, D., Arthur, J., Garber-Yonts, B., Haight, R., Kagan, J., Starfield, A., Tobalske, C., 2008. Where to put things? Spatial land management to sustain biodiversity and economic returns. Biological Conservation 141(6) 1505-1524. Polasky, S., Nelson, E., Lonsdorf, E., Fackler, P., Starfield, A., 2005. Conserving species in a working landscape: land use with biological and economic-objectives (vol 15, pg 1387, 2005). Ecological Applications 15(6) 2209-2209.

Pouzols, F.M., Toivonen, T., Di Minin, E., Kukkala, A.S., Kullberg, P., Kuustera, J., Lehtomaki, J., Tenkanen, H., Verburg, P.H., Moilanen, A., 2014. Global protected area expansion is compromised by projected land-use and parochialism. Nature 516(7531) 383-386.

Pressey, R.L., Bottrill, M.C., 2008. Opportunism, threats, and the evolution of Systematic Conservation Planning. Conservation Biology 22(5) 1340-1345. 
Pressey, R.L., Cabeza, M., Watts, M.E., Cowling, R.M., Wilson, K.A., 2007. Conservation planning in a changing world. Trends in Ecology \& Evolution 22(11) 583-592.

Pressey, R.L., Possingham, H.P., Margules, C.R., 1996. Optimality in reserve selection algorithms: When does it matter and how much? Biological Conservation 76(3) 259-267.

Prieto-Torres, D.A., Navarro-Sigüenza, A.G., Santiago-Alarcon, D., Rojas-Soto, O.R., 2016. Response of the endangered tropical dry forests to climate change and the role of Mexican Protected Areas for their conservation. Global Change Biology 22(1) 364-379.

Proença, V., Martin, L.J., Pereira, H.M., Fernandez, M., McRae, L., Belnap, J., Böhm, M., Brummitt, N., GarcíaMoreno, J., Gregory, R.D., Honrado, J.P., Jürgens, N., Opige, M., Schmeller, D.S., Tiago, P., van Swaay, C.A.M., 2017. Global biodiversity monitoring: From data sources to Essential Biodiversity Variables. Biological Conservation 213 256-263.

Ravindran, A.R., 2008. Operations Research Applications. CRC Press.

Rayfield, B., Fortin, M.-J., Fall, A., 2010. The sensitivity of least-cost habitat graphs to relative cost surface values. Landscape Ecology 25(4) 519-532.

Rayfield, B., Fortin, M.-J., Fall, A., 2011. Connectivity for conservation: a framework to classify network measures. Ecology 92(4) 847-858.

Regan, H.M., Ben-Haim, Y., Langford, B., Wilson, W.G., Lundberg, P., Andelman, S.J., Burgman, M.A., 2005. Robust decision-making under severe uncertainty for conservation management. Ecological Applications 15(4) 1471-1477.

Regan, H.M., Ensbey, M., Burgman, M.A., 2009. Conservation prioritization and uncertainty in planning inputs, In: Moilanen, A., Wilson, K.A., Possingham, H. (Eds.), Spatial Conservation Prioritization: Quantitative Methods and Computational Tools. Oxford University Press: Oxford, UK, pp. 145-157.

Regos, A., D'Amen, M., Titeux, N., Herrando, S., Guisan, A., Brotons, L., 2016. Predicting the future effectiveness of protected areas for bird conservation in Mediterranean ecosystems under climate change and novel fire regime scenarios. Diversity and Distributions 22(1) 83-96.

Renwick, A.R., Bode, M., Venter, O., 2015. Reserves in Context: Planning for Leakage from Protected Areas. PLoS ONE 10(6) e0129441.

Reyers, B., Polasky, S., Tallis, H., Mooney, H.A., Larigauderie, A., 2012. Finding common ground for biodiversity and ecosystem services. BioScience 62(5) 503-507.

Rissman, A.R., Owley, J., Shaw, M.R., Thompson, B., 2015. Adapting conservation easements to climate change. Conservation Letters 8(1) 68-76.

Rodrigues, A.S., Cerdeira, J.O., Gaston, K.J., 2000. Flexibility, efficiency, and accountability: adapting reserve selection algorithms to more complex conservation problems. Ecography 23(5) 565-574. 
Sanderlin, J.S., Block, W.M., Ganey, J.L., 2014. Optimizing study design for multi-species avian monitoring programs. Journal of Applied Ecology n/a-n/a.

Sawyer, S.C., Epps, C.W., Brashares, J.S., 2011. Placing linkages among fragmented habitats: do least-cost models reflect how animals use landscapes? Journal of Applied Ecology 48 668-678.

Schapaugh, A.W., Tyre, A.J., 2012. Bayesian networks and the quest for reserve adequacy. Biological Conservation 152(0) 178-186.

Seddon, N., Mace, G.M., Naeem, S., Tobias, J.A., Pigot, A.L., Cavanagh, R., Mouillot, D., Vause, J., Walpole, M., 2016. Biodiversity in the Anthropocene: prospects and policy. Proceedings of the Royal Society B:

Biological Sciences 283(1844).

Sessions, J., 1992. Solving for habitat connections as a Steiner network problem Forest Science 38 203207.

Sewell, D., Guillera-Arroita, G., Griffiths, R.A., Beebee, T.J.C., 2012. When Is a Species Declining? Optimizing Survey Effort to Detect Population Changes in Reptiles. PLoS ONE 7(8) e43387.

Shaw, M.R., Klausmeyer, K., Cameron, D.R., Mackenzie, J., Roehrdanz, P., 2012. Economic costs of achieving current conservation goals in the future as climate changes. Conservation Biology 26(3) 385-396.

Smith, P.G.R., Theberge, J.B., 1987. Evaluating natural areas using multiple criteria: theory and practice. Journal of Environmental Management 11 447-460.

Song, M.-L., Fisher, R., Wang, J.-L., Cui, L.-B., 2018. Environmental performance evaluation with big data: theories and methods. Annals of Operations Research 270(1) 459-472.

Steffen, W., Rockström, J., Richardson, K., Lenton, T.M., Folke, C., Liverman, D., Summerhayes, C.P., Barnosky, A.D., Cornell, S.E., Crucifix, M., Donges, J.F., Fetzer, I., Lade, S.J., Scheffer, M., Winkelmann, R., Schellnhuber, H.J., 2018. Trajectories of the Earth System in the Anthropocene. Proceedings of the National Academy of Sciences.

Strange, N., Thorsen, B.J., Bladt, J., 2006. Optimal reserve selection in a dynamic world. Biological Conservation 131(1) 33-41.

Sutton, N.J., Armsworth, P.R., 2014. The grain of spatially referenced economic cost and biodiversity benefit data and the effectiveness of a cost targeting strategy. Conservation Biology 28(6) 1451-1461. Tóth, S.F., Haight, R.G., Rogers, L.W., 2011. Dynamic reserve selection: optimal land retention with landprice feedbacks. Operations Research 59(5) 1059-1078.

Tulloch, V.J., Possingham, H.P., Jupiter, S.D., Roelfsema, C., Tulloch, A.I.T., Klein, C.J., 2013. Incorporating uncertainty associated with habitat data in marine reserve design. Biological Conservation 162(0) 41-51. United Nations, 2015. Transforming our world: the 2030 Agenda for Sustainable Development A/RES/70/1. United Nations General Assembly, p. 41. 
Urban, D., Keitt, T., 2001. Landscape connectivity: a graph-theoretic perspective. Ecology 82(5) 12051218.

Urban, M.C., 2015. Accelerating extinction risk from climate change. Science 348(6234) 571-573.

Venter, O., Magrach, A., Outram, N., Klein, C.J., Possingham, H.P., Di Marco, M., Watson, J.E.M., 2018. Bias in protected-area location and its effects on long-term aspirations of biodiversity conventions. Conservation Biology 32(1) 127-134.

Wade, P.R., 2000. Bayesian Methods in Conservation Biology. Conservation Biology 14(5) 1308-1316.

Wang, Y., Önal, H., 2015. Optimal design of compact and connected nature reserves for multiple species. Conservation Biology n/a-n/a.

Warman, L.D., Sinclair, A.R.E., Scudder, G.G.E., Klinkenberg, B., Pressey, R.L., 2004. Sensitivity of systematic reserve selection to decisions about scale, biological data, and targets: Case study from Southern British Columbia. Conservation Biology 18(3) 655-666.

Watson, J.E.M., Grantham, H.S., Wilson, K.A., Possingham, H.P., 2011. Systematic Conservation Planning: Past, Present and Future, In: Ladle, R.J., Whittaker, R.J. (Eds.), Conservation Biogeography. WileyBlackwell, pp. 136-160.

Watts, M.E., Ball, I.R., Stewart, R.S., Klein, C.J., Wilson, K., Steinback, C., Lourival, R., Kircher, L., Possingham, H.P., 2009. Marxan with Zones: Software for optimal conservation based land- and sea-use zoning. Environmental Modelling \& Software.

Westphal, M.I., Pickett, M., Getz, W.M., Possingham, H.P., 2003. The use of stochastic dynamic programming in optimal landscape reconstruction for metapopulations. Ecological Applications 13(2) 543-555.

Wiersma, Y.F., Nudds, T.D., 2006. Conservation targets for viable species assemblages in Canada: are percentage targets appropriate? . Biodiversity and Conservation 15(14) 4555-4567.

Williams, B.K., Johnson, F.A., 2013. Confronting dynamics and uncertainty in optimal decision making for conservation. Environmental Research Letters 8(2) 025004.

Williams, J.C., 2002. A zero-one programming model for contiguous land acquisition. Geographical Analysis 34(4) 330-349.

Williams, J.C., ReVelle, C.S., Levin, S.A., 2004. Using mathematical optimization models to design nature reserves. Frontiers in Ecology and the Environment 2(2) 98-105.

Williams, P., Hannah, L., Andelman, S., Midgley, G., Araujo, M., Hughes, G., Manne, L., Martinez-Meyer, E., Pearson, R., 2005. Planning for climate change: Identifying minimum-dispersal corridors for the Cape Proteaceae. Conservation Biology 19(4) 1063-1074.

Wilson, K.A., Lulow, M., Burger, J., Fang, Y.-C., Andersen, C., Olson, D., O’Connell, M., McBride, M.F., 2011. Optimal restoration: accounting for space, time and uncertainty. Journal of Applied Ecology no-no. 
Wilson, K.A., McBride, M.F., Bode, M., Possingham, H.P., 2006. Prioritizing global conservation efforts. Nature 440(7082) 337-340.

Wise, R.M., Reyers, B., Guo, C., Midgley, G.F., De Lange, W., 2012. Costs of expanding the network of protected areas as a response to climate change in the Cape Floristic Region. Conservation Biology 26(3) 397-407.

With, K.A., 2002. Using Percolation Theory to Assess Landscape Connectivity and Effects of Habitat Fragmentation, In: Gutzwiller, K.J. (Ed.), Applying Landscape Ecology in Biological Conservation. Springer New York: New York, NY, pp. 105-130.

Woodward, R.T., Tomberlin, D., 2014. Practical Precautionary Resource Management Using Robust Optimization. Environmental Management 54(4) 828-839.

Yemshanov, D., Haight, R.G., Koch, F.H., Lu, B., Venette, R., Fournier, R.E., Turgeon, J.J., 2017. Robust surveillance and control of invasive species using a scenario optimization approach. Ecological Economics 133 86-98.

Yokomizo, H., Haccou, P., Iwasa, Y., 2004. Multiple-year optimization of conservation effort and monitoring effort for a fluctuating population. Journal of Theoretical Biology 230(2) 157-171. 